\title{
Review Article \\ Clinical Usefulness of Response Profiles to Rapidly Incremental Cardiopulmonary Exercise Testing
}

\author{
Roberta P. Ramos, ${ }^{1}$ Maria Clara N. Alencar, ${ }^{1}$ Erika Treptow, ${ }^{1}$ Flávio Arbex, ${ }^{1}$ \\ Eloara M. V. Ferreira, ${ }^{1}$ and J. Alberto Neder ${ }^{1,2}$ \\ ${ }^{1}$ Pulmonary Function and Clinical Exercise Physiology Unit (SEFICE), Division of Respiratory Diseases, Department of Medicine, \\ Federal University of Sao Paulo (UNIFESP), Rua Francisco de Castro 54, Vila Mariana, 04020-050 São Paulo, SP, Brazil \\ ${ }^{2}$ Division of Respiratory and Critical Care Medicine, Department of Medicine, Queen's University and Kingston General Hospital, \\ Richardson House, 102 Stuart Street, Kingston, ON, Canada K7L 2V6
}

Correspondence should be addressed to J. Alberto Neder; nederalb@gmail.com

Received 29 July 2012; Revised 17 December 2012; Accepted 15 January 2013

Academic Editor: Bruce D. Johnson

Copyright (C) 2013 Roberta P. Ramos et al. This is an open access article distributed under the Creative Commons Attribution License, which permits unrestricted use, distribution, and reproduction in any medium, provided the original work is properly cited.

\begin{abstract}
The advent of microprocessed "metabolic carts" and rapidly incremental protocols greatly expanded the clinical applications of cardiopulmonary exercise testing (CPET). The response normalcy to CPET is more commonly appreciated at discrete time points, for example, at the estimated lactate threshold and at peak exercise. Analysis of the response profiles of cardiopulmonary responses at submaximal exercise and recovery, however, might show abnormal physiologic functioning which would not be otherwise unraveled. Although this approach has long been advocated as a key element of the investigational strategy, it remains largely neglected in practice. The purpose of this paper, therefore, is to highlight the usefulness of selected submaximal metabolic, ventilatory, and cardiovascular variables in different clinical scenarios and patient populations. Special care is taken to physiologically justify their use to answer pertinent clinical questions and to the technical aspects that should be observed to improve responses' reproducibility and reliability. The most recent evidence in favor of (and against) these variables for diagnosis, impairment evaluation, and prognosis in systemic diseases is also critically discussed.
\end{abstract}

\section{Introduction}

Cardiopulmonary exercise testing (CPET) provides a means of unraveling abnormal physiologic functioning which may not be apparent at rest $[1,2]$. The advent of microprocessed CPET systems [3] increased our technical capabilities in recording several variables throughout a single exercise bout-even of a relatively "short" duration of 10 minutes $[4,5]$. The response normalcy to rapidly incremental CPET is more commonly judged by comparing the observed values at discrete time points (e.g., at the estimated lactate threshold (LT) and at peak exercise) with those previously obtained in apparently healthy subjects $[6,7]$. It should be noted, however, that relying only in such discrete analysis leads to substantial loss of physiologic information given by the observation of the responses profiles during submaximal exercise and recovery [8-11].
In this context, authoritative textbooks $[2,12]$ and guidelines $[13,14]$ advocated that the trending of certain variables is a crucial component of the interpretative strategy as they might show substantial abnormalities even when the discrete values are still within the expected range [15-17]. Moreover, the response dynamics are highly reproducible [811], encompassing a range of exercise intensities which are likely to be faced by the patients in daily life [18-26]. Although the scientific foundations supporting their use have long been established, [8-17] they are still not routinely assessed and clinically valued in practice.

The purpose of this brief review, therefore, is to emphasize the practical usefulness of analyzing the response profiles of selected variables during rapidly-incremental CPET. Special care is taken to physiologically justify their use to answer relevant clinical questions and to the technical details that 


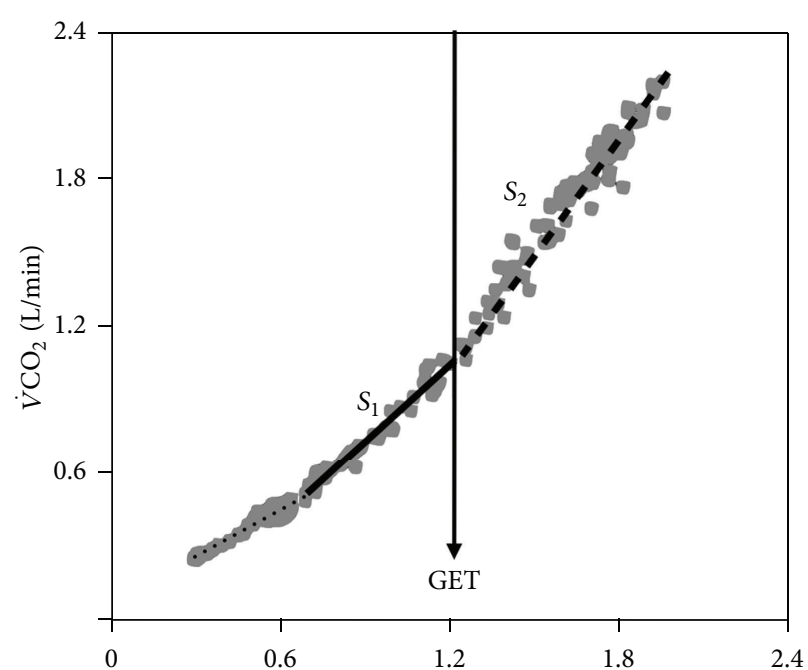

(a)

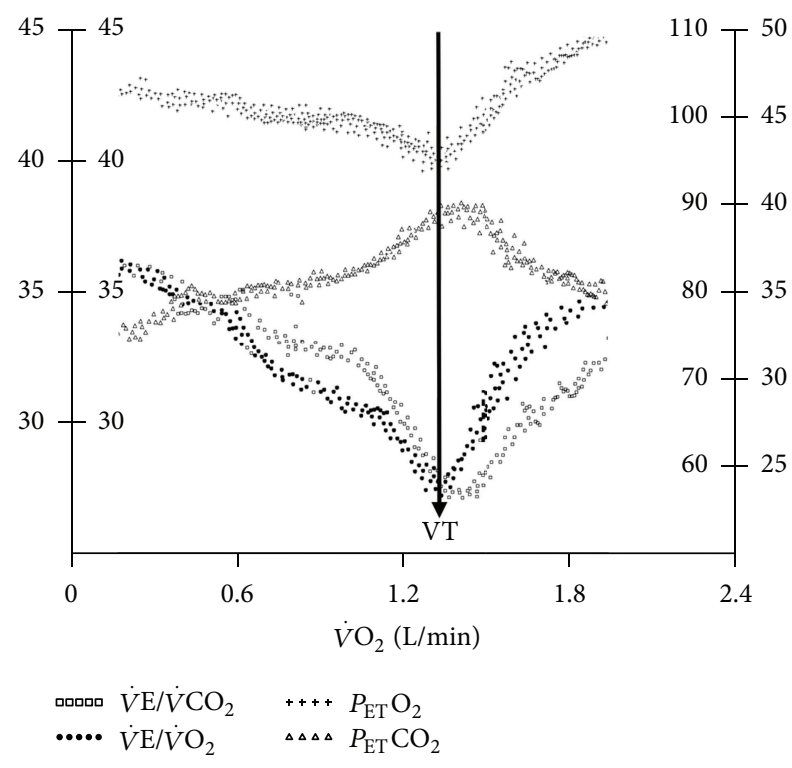

(b)

FIgURE 1: Noninvasive estimation of the lactate threshold by the $V$-slope method (gas exchange threshold (GET), panel (a)) and the ventilatory method (ventilatory threshold (VT), panel (b)) in a normal subject. Note that the GET slightly precedes the VT as the later depends on the ventilatory response to the "extra- $\mathrm{CO}_{2}$ " generated by buffering of $\mathrm{H}^{+}$associated with (lactate) increase. $S_{1}$ and $S_{2}$ refer to the two sequential slopes (before and after the GET) with $S_{2}$ being characteristically steeper than $S_{1}$ (i.e., slope inclination $>1$.)

should be observed to improve responses' reproducibility and reliability. The response profiles to be discussed, however, are applicable to ramp-incremental [4] cycle ergometry, and the practitioner should be aware that different patterns of response can be anticipated if other ergometers (e.g., treadmill) and protocols (e.g., step-like) are used.

\section{Metabolic Responses}

\subsection{Estimated Lactate Threshold}

2.1.1. Physiological Background. The rate at which arterial lactate anions $\left[\mathrm{Lac}^{-}\right]_{\mathrm{a}}$ and the associated proton $\left(\mathrm{H}^{+}\right)$ accumulate as exercise progresses is directly related to the ratio between lactic acid (LA) release as a final byproduct of muscle anaerobic glycolysis and LA clearance by metabolism and buffering [29-31]. Although there seems to exist a period of time-not a discrete time point-in which LA production exceeds its rate of clearance, the term LA "threshold" (LT) $[32,33]$ is widely used. LA production increases as tissue $\mathrm{O}_{2}$ delivery diminishes [34] though some LA can be produced without any evidence of tissue hypoxia [35]. This justifies the notion that LA release during exercise is a reasonably sensitive (albeit non-specific) [36] marker of tissue anaerobiosis.

LA dissociates fast in $\mathrm{Lac}^{-}$and $\mathrm{H}^{+}$in the physiological $\mathrm{pH}$; that is, it is a strong acid. Plasma bicarbonate $\left(\mathrm{HCO}_{3}{ }^{-}\right)$is the main buffer of lactic acidosis leading to the formation of carbonic acid $\left(\mathrm{H}_{2} \mathrm{CO}_{3}\right)$ which in turn dissociates into carbon dioxide $\left(\mathrm{CO}_{2}\right)$ and water; that is,

$$
\mathrm{H}^{+} \mathrm{Lac}^{-}+\mathrm{HCO}_{3}^{-} \Longleftrightarrow \mathrm{H}_{2} \mathrm{CO}_{3} \Longleftrightarrow \mathrm{CO}_{2}+\mathrm{H}_{2} \mathrm{O} \text {. }
$$

Although this reaction has the advantage to turn a fixed acid into a volatile gas, the "extra- $\mathrm{CO}_{2}$ " (approximately $22-26 \mathrm{~mL}$ of additional $\mathrm{CO}_{2}$ is produced from each $\mathrm{mEq}$ decrease of $\left.\left[\mathrm{HCO}_{3}{ }^{-}\right]\right)$[31] derived from buffering of $\mathrm{Lac}^{-}$associated protons will not only accelerate $\mathrm{CO}_{2}$ output $\left(\dot{V}_{\mathrm{CO}_{2}}\right)$ relative to $\mathrm{O}_{2}$ uptake $\left(\dot{V}_{\mathrm{O}_{2}}\right)$ but also stimulate ventilation $\left(\dot{V}_{\mathrm{E}}\right)$. These phenomena underlie the techniques for a noninvasive estimation of the LT.

2.1.2. Technical Considerations. As $\mathrm{LA}$ is buffered by $\mathrm{HCO}_{3}{ }^{-}$, $\dot{V}_{\mathrm{CO}_{2}}$ increases (1) out of proportion of $\dot{V}_{\mathrm{O}_{2}}$, and a plot between these variables will show a discernible breakpoint; that is, the $\dot{V}_{\mathrm{CO}_{2}}-\dot{V}_{\mathrm{O}_{2}}$ relationship evidences an increased slope at the point of $\left[\mathrm{Lac}^{-}\right]_{\mathrm{a}}$ increase. This is more commonly referred as the gas exchange threshold and determined by the $V$-slope method (Figure 1(a)) [37]. Increase in $\dot{V}_{\mathrm{CO}_{2}}$ will drive $\dot{V}_{\mathrm{E}}$ in its direct proportion leading the latter to increase faster than $\dot{V}_{\mathrm{O}_{2}}$. The consequent increase in $\dot{V}_{\mathrm{E}} / \dot{V}_{\mathrm{O}_{2}}$ (and the endtidal partial pressure for $\left.\mathrm{O}_{2}, P_{\mathrm{ET}} \mathrm{O}_{2}\right)$ with a stable $\dot{V}_{\mathrm{E}} / \dot{V}_{\mathrm{CO}_{2}}$ (and $P_{\mathrm{ET}} \mathrm{CO}_{2}$ ) establishes the so-called ventilatory threshold (Figure 1(b)) [38]. It should be noted that despite reflecting the same phenomenon (LA buffering), the gas exchange threshold slightly precedes the ventilatory threshold (VT) (Figure 1). After the LT, $\dot{V}_{\mathrm{E}} / \dot{V}_{\mathrm{CO}_{2}}$ and $P_{\mathrm{ET}} \mathrm{CO}_{2}$ remain stable for a variable period of time during the "isocapnic buffering". However, as more $\mathrm{H}^{+}$is released with further increases in work rate, $\dot{V}_{\mathrm{E}}$ eventually increases out of proportion to $\dot{V}_{\mathrm{CO}_{2}}$ at the respiratory compensation point (RCP) thereby leading to alveolar hyperventilation and progressive reductions in $P_{\mathrm{ET}} \mathrm{CO}_{2}$ towards the end of the test (Figure 1(b)).

Irrespective of the denomination, the following technical aspects for the LT estimation should be noted: 
(1) automatic estimations (by the CPET software) should be viewed with caution and routinely double-checked with manually determined values;

(2) if an unitary tangent is used to estimate the LT in the $V$-slope plot, the range of $\dot{V}_{\mathrm{O}_{2}}$ and $\dot{V}_{\mathrm{CO}_{2}}$ values should be the same as any discrepancy would invalidate its underlying mathematical (and physiological) principles [37] (Figure 1(b));

(3) use of discrete $\mathrm{R}\left(\dot{V}_{\mathrm{CO}_{2}} / \dot{V}_{\mathrm{O}_{2}}\right)$ values (i.e., $>1$ from tabular data) as indicative of the LT might lead to erroneous estimations;

(4) $\dot{V}_{\mathrm{O}_{2}}$ at any particular WR during a ramp-incremental test is lower than the steady-state $\dot{V}_{\mathrm{O}_{2}}$ value at that same WR due to a variable $\dot{V}_{\mathrm{O}_{2}}$ kinetics delay. As a result, the WR corresponding to $\dot{V}_{\mathrm{O}_{2}}$ LT precedes the WR in which the LT was identified by approximately 30-45 s (or even more in patients) [4]. Accordingly, if one is interested in exercising a subject at the $\dot{V}_{\mathrm{O}_{2}}$ LT, the selected WR should lead the WR-LT by this timeframe;

(5) a given change in $\dot{V}_{\mathrm{E}}$ has a greater effect on $\mathrm{CO}_{2}$ release than $\mathrm{O}_{2}$ uptake by the lungs; consequently, preexercise hyperventilation may deplete the amount of $\mathrm{CO}_{2}$ stored in the body without major effects on $\mathrm{O}_{2}$ stores [39]. As the body capacitance for $\mathrm{CO}_{2}$ increases during the early phase of the ramp, repletion of the $\mathrm{CO}_{2}$ stores slows $\dot{V}_{\mathrm{CO}_{2}}$ relative to $\dot{V}_{\mathrm{O}_{2}}$; that is, $\dot{V}_{\mathrm{CO}_{2}{ }^{-}}$ $\dot{V}_{\mathrm{O}_{2}}$ slope in this region becomes shallow (" $S_{1}$ " in Figure 1(a)). As the body $\mathrm{CO}_{2}$ reservoirs are filled in with exercise progression, the rate of $\mathrm{CO}_{2}$ storage will decrease thereby accelerating $\dot{V}_{\mathrm{CO}_{2}}$ relative to $\dot{V}_{\mathrm{CO}_{2}}$ [40]. This might mistakenly suggest the onset of lactic acidosis, that is, a "pseudo-LT" [41]. Precautions should therefore be taken to avoid hyperventilation prior to the noninvasive estimation of LT by the $V$ slope method;

(6) LT should always be expressed relative to predicted $\dot{V}_{\mathrm{O}_{2}}$ peak not to the attained $\dot{V}_{\mathrm{O}_{2}}$ peak, especially in patient populations where the latter procedure might create a false concept of preserved (or even increased) $\dot{V}_{\mathrm{O}_{2}}$ LT, and

(7) $\dot{V}_{\mathrm{O}_{2}}$ peak declines with senescence at a steeper rate than $\dot{V}_{\mathrm{O}_{2}}$ LT; that is, $\dot{V}_{\mathrm{O}_{2}}$ LT (\% $\dot{V}_{\mathrm{O}_{2}}$ peak) increases as a function of age in both genders [41-43].

2.1.3. Clinical Usefulness. The physiologic changes associated with $\left[\mathrm{Lac}^{-}\right]_{\mathrm{a}}$ and $\mathrm{H}^{+}$accumulation (e.g., metabolic acidosis, impaired muscle contraction, hyperventilation, and altered $\dot{V}_{\mathrm{O}_{2}}$ kinetics) are important to document clinically as they are associated with reduced cardiopulmonary performance. An early LT is a marker of impaired aerobic metabolism [4449] due to insufficient $\mathrm{O}_{2}$ delivery, increased recruitment of fast-twitch type II fibers which are metabolically less efficient than the slow-twitch type I fibers (i.e., have a greater $\mathrm{O}_{2} /$ ATP ratio), and/or mitochondrial enzymatic dysfunction. The isolated analysis of the LT does not allow the differentiation of cardiovascular limitation from sedentarity though a severely decreased LT (e.g., <40\% predicted $\dot{V}_{\mathrm{O}_{2}}$ peak) [6] is more frequently found in patients. A low LT has been found useful to predict an increased risk of post-operatory complications in the elderly $[50,51]$, worse prognosis in chronic heart failure (CHF) [52], and disease severity in pulmonary arterial hypertension (PAH) [53]. On the other hand, improvements in LT after pharmacological and nonpharmacological interventions have been associated with increased functional performance in a range of clinical populations [54-69]. Although there is lack of evidence that training at (or above) the $\dot{V}_{\mathrm{O}_{2}}$ LT is essential to improve exercise capacity in patients with $\mathrm{CHF}$, coronary artery disease (CAD), and chronic obstructive pulmonary disease (COPD), training at higher intensities elicits larger physiological adaptations in less severe patients who are able to tolerate such regimens [54, 70, 71]. Training at the $\dot{V}_{\mathrm{O}_{2}}$ LT also seems to reduce the risk of complications during early phases of cardiac rehabilitation [72, 73]. In patients with COPD, however, LT cannot always be identified (even using the $V$-slope method), and when identified it varies widely as expressed in $\dot{V}_{\mathrm{O}_{2}} \%$ peak [74]. In fact, important subjective improvements after rehabilitation can be found despite the lack of measurable physiological effects [75] which casts doubt on its usefulness to target exercise training intensity in these patients.

\section{2. $\Delta$ Oxygen Uptake $\left(\dot{V}_{\mathrm{O}_{2}}\right) / \Delta$ Work Rate $(W R)$}

2.2.1. Physiological Background. From a relatively constant value of $500 \mathrm{~mL} / \mathrm{min}$ at unloaded pedaling, $\dot{V}_{\mathrm{O}_{2}}$ increases linearly as exercise progresses during a rapidly-incremental exercise test [4]. The slope of the $\Delta \dot{V}_{\mathrm{O}_{2}} / \Delta \mathrm{WR}$ relationship, therefore, is an index of the overall gain of the $\dot{V}_{\mathrm{O}_{2}}$ response, and normal values would indicate adequate metabolic cost for the production of a given power output $[4,8]$.

2.2.2. Technical Considerations. For an accurate calculation of the $\Delta \dot{V}_{\mathrm{O}_{2}} / \Delta \mathrm{WR}$ slope, any delay in $\dot{V}_{\mathrm{O}_{2}}$ increase at the start of the ramp or any eventual plateau near the end of exercise should be discarded (Figures 2(a) and 4). Considering that the LT can potentially distort the response's linearity [157160], it is advisable to check if there is an inflection point in the $\Delta \dot{V}_{\mathrm{O}_{2}} / \Delta \mathrm{WR}$ at the LT. If this is discernible, the slope should be calculated over the sub-LT range.

2.2.3. Interpretative Issues. $\Delta \dot{V}_{\mathrm{O}_{2}} / \Delta \mathrm{WR}$ is not significantly influenced by the training status, ageing, or gender (Figure 3(a)) $[2,10,12-14]$. A shallow $\Delta \dot{V}_{\mathrm{O}_{2}} / \Delta \mathrm{WR}$ over the entire range of values and/or a shift from a linearly increasing profile to a shallower rate of change has been shown to be indicative of circulatory dysfunction [77-80] (Figure 4) and severe impairment in mitochondrial function [81]. The latter pattern of response has been found to enhance ECG sensitivity to detect myocardial ischemia [82-86], and some studies suggested that it might be useful to unravel early abnormalities in the coronary microcirculation $[87,88]$. 

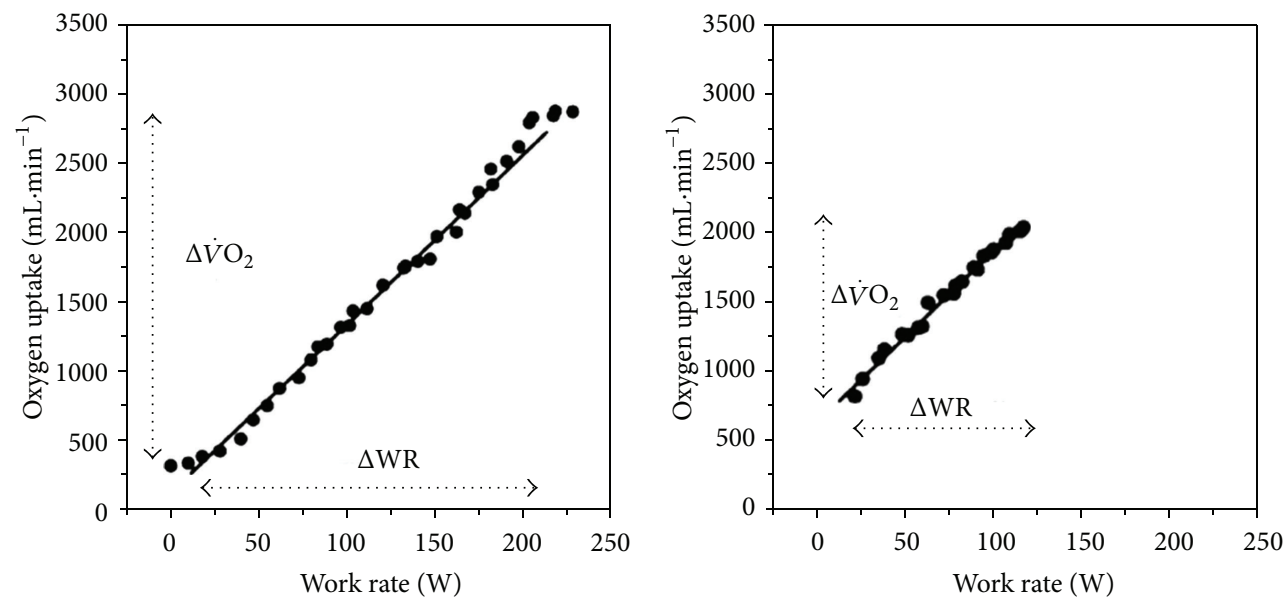

(a)
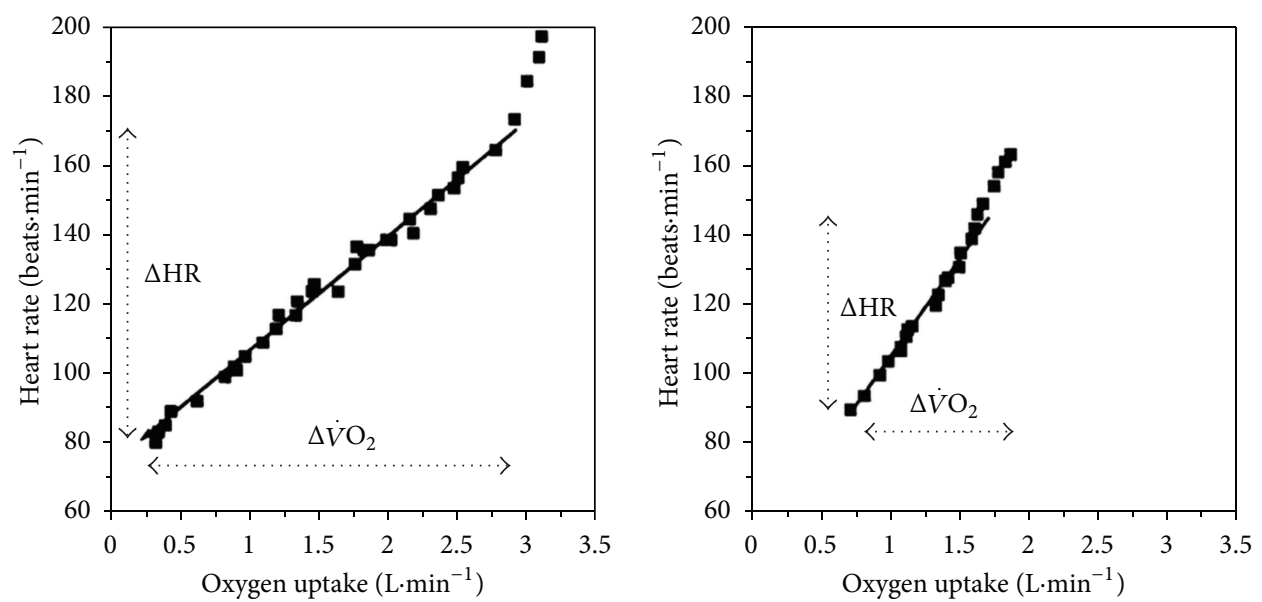

(b)
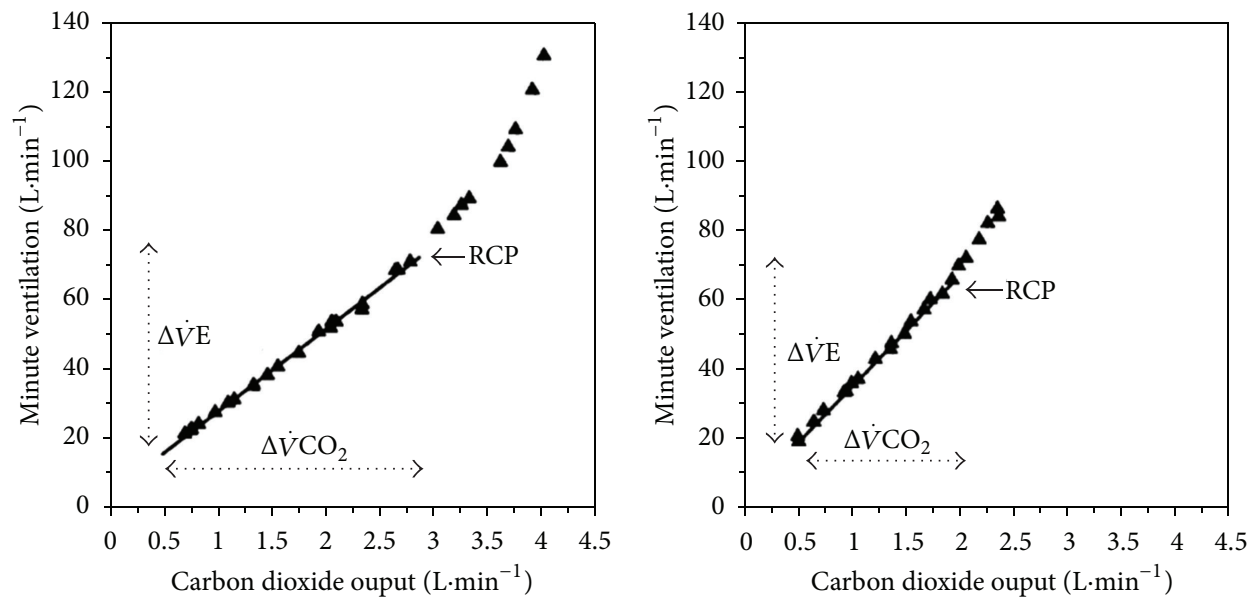

(c)

FIgURE 2: Procedures to establish 3 dynamic submaximal relationships by simple linear regression during incremental CPET in young (24yr-old, left panels) and old (70-yr-old, right panels) subjects. (a) $\Delta$ oxygen uptake $\left(\dot{V}_{\mathrm{O}_{2}}\right) / \Delta$ work rate (WR); (b) $\Delta$ heart rate/ $\Delta \dot{V}_{\mathrm{O}_{2}}$ (c) $\Delta$ minute ventilation $\left(\dot{V}_{\mathrm{E}}\right) / \Delta$ carbon dioxide output $\left(\dot{V}_{\mathrm{CO}_{2}}\right)$. The arrows show the range of values considered for analysis. RCP is the respiratory compensation point. (Modified with permission from [10].) 

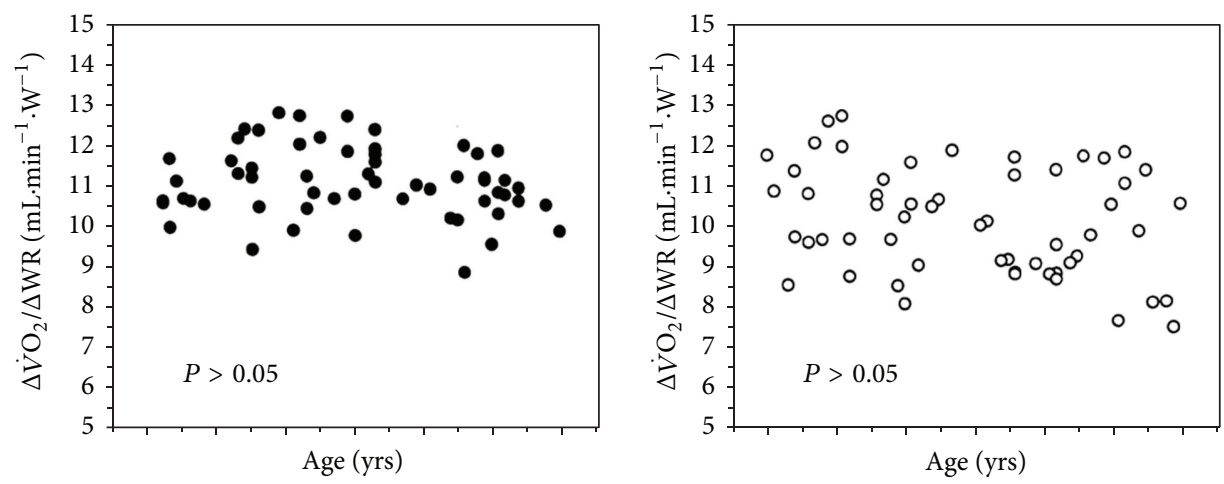

(a)
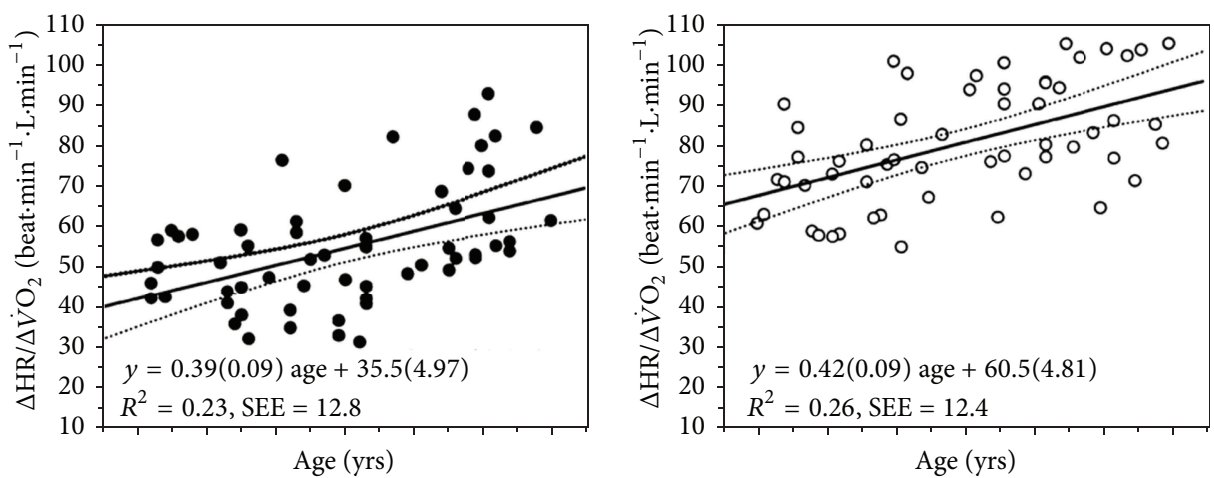

(b)
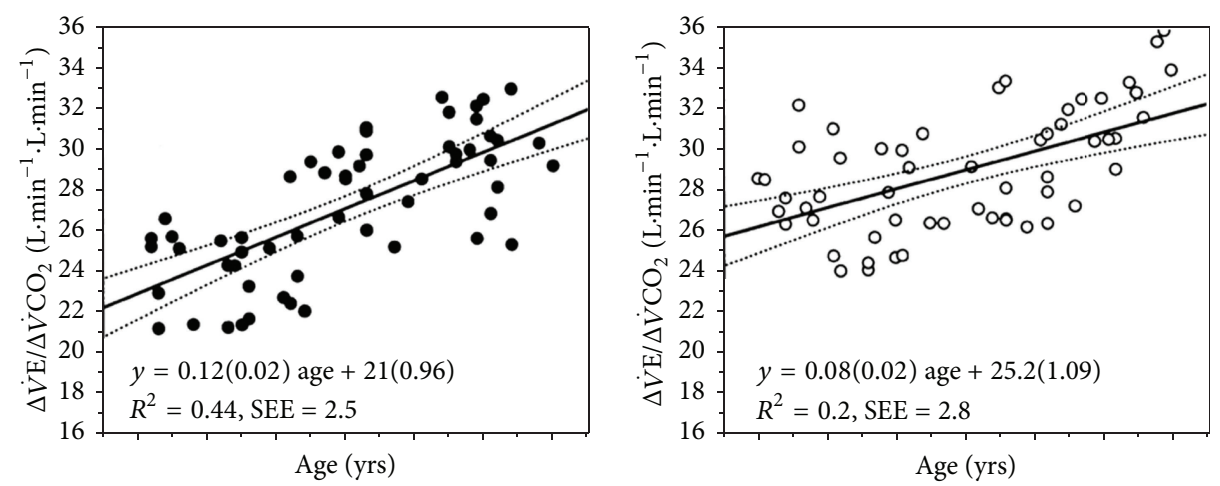

(c)

Figure 3: The submaximal relationships depicted in Figure 2 as a function of age in males (left panels) and females (right panels). Regression lines are shown with their respective $95 \%$ confidence intervals for those relationships in which the variables were influenced by age. Regression coefficients and intercepts of the linear prediction equations are depicted with their respective standard error of the estimate (SEE). (Modified with permission from [10]).

\section{3. $\dot{V}_{\mathrm{O}_{2}}$ Efficiency}

2.3.1. Physiological Background. $\dot{V}_{\mathrm{E}}$ increases curvilinearly relative to $\dot{V}_{\mathrm{O}_{2}}$ in response to a ramp-incremental exercise test. At least in theoretical grounds, several variables known to interfere with both $\dot{V}_{\mathrm{E}}$ and $\dot{V}_{\mathrm{O}_{2}}$ would bear an influence in this relationship; that is, it is deemed to be modulated by cardiovascular, pulmonary, and muscular factors [161-168]. Most authors have expressed the $\dot{V}_{\mathrm{E}}-\dot{V}_{\mathrm{O}_{2}}$ relationship with $\dot{V}_{\mathrm{O}_{2}}$ as the dependent variable $[89,165,169]$. In this construct, higher $\dot{V}_{\mathrm{O}_{2}}$ values (or steeper rates of change) for a given $\dot{V}_{\mathrm{E}}$ would indicate a more "efficient" $\mathrm{O}_{2}$ uptake by the lungs. It should be emphasized, however, that exercise $\dot{V}_{\mathrm{E}}$ is more closely related to $\dot{V}_{\mathrm{CO}_{2}}$ than $\dot{V}_{\mathrm{O}_{2}}$ [170] which makes the concept of $\dot{V}_{\mathrm{O}_{2}}$ efficiency prone to misinterpretation (see Section 2.3.3).

2.3.2. Technical Considerations. Baba and coworkers [165] proposed a logarithmic transformation of $\dot{V}_{\mathrm{E}}$ over the entire exercise period to "linearize" this relationship, the so-called $\dot{V}_{\mathrm{O}_{2}}$ efficiency slope (OUES) (Figure 5(a)). More recently, Sun 


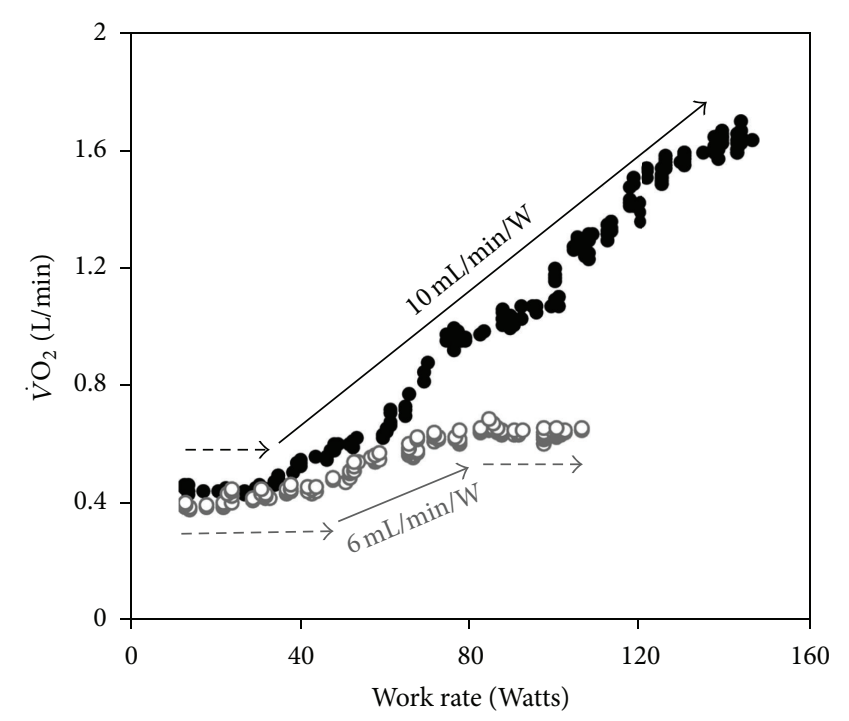

0000 Before surgery

$\cdots$ After surgery

FIGURE 4: Oxygen uptake $\left(\dot{V}_{\mathrm{O}_{2}}\right) /$ work rate (WR) relationship during ramp-incremental CPET before and after pulmonary endarterectomy in a 21-year-old male with thromboembolic occlusion of the left pulmonary artery. Note that after the surgery, peak $\dot{V}_{\mathrm{O}_{2}}$ increased not only due to a higher peak WR but also owing to a large improvement in $\Delta \dot{V}_{\mathrm{O}_{2}} / \Delta \mathrm{WR}$.

et al. $[89,169]$ expressed the OUE as a ratio $\left(\dot{V}_{\mathrm{O}_{2}} / \dot{V}_{\mathrm{E}}\right.$ in $\left.\mathrm{mL} / \mathrm{L}\right)$ over time which, as expected, gives a mirror image of the ventilatory equivalent for $\mathrm{O}_{2}$. The authors proposed the term OUE plateau (OUEP) to the $90 \mathrm{~s}$-average of the highest consecutive $\dot{V}_{\mathrm{O}_{2}} / \dot{V}_{\mathrm{E}}$ measurements; that is, the values just before the LT (Figure 5(b)). Although they reported that OUEP was more reproducible than OUES, this was not yet independently confirmed. It has been claimed that both relationships are independent of interobserver variability and effort [90, 164, 171-173]. However, Williamson et al. [173] recently found that there was a significant increase in OUES as exercise moved from low to moderate intensity with a peak value at an RER value of 1.0. Oscillatory breathing (see Section 3.3) has been found to interfere little with OUE estimations [89]. It should be recognized that both OUES and OUEP require separate computation though some commercially available CPET systems allow logarithmic transformations for OUES calculation.

2.3.3. Interpretative Issues. It is well established that exercise hyperpnea is under stronger influence of $P_{\mathrm{a}} \mathrm{CO}_{2}$ and $\mathrm{pH}_{\mathrm{a}}$ (rather than $P_{\mathrm{a}} \mathrm{O}_{2}$ ) [170]. As detailed later (Section 3.1), changes in $\mathrm{CO}_{2}$ set-point and ventilatory "efficiency" control the rate of $\mathrm{CO}_{2}$ clearance. This brings substantial uncertainty on the exact physiological meaning of a disturbed relationship between $\dot{V}_{\mathrm{E}}$ and $\dot{V}_{\mathrm{O}_{2}}$. Nevertheless, the literature pertaining to the clinical usefulness of OUES is rather vast in $\mathrm{CHF}[90,164,165,167,171,172]$, and interest in this relationship has been spread to other populations (cystic fibrosis, and surgical candidates) $[174,175]$. A number of studies have found that OUES is strongly correlated with $\dot{V}_{\mathrm{O}_{2}}$ peak $[90,164,165,167,171,172,176,177]$ and may hold prognostic value in CHF $[18,89-94]$. However, the prognostic advantage of OUES over $\Delta \dot{V}_{\mathrm{E}} / \Delta \dot{V}_{\mathrm{CO}_{2}}$ slope remains unclear $[178,179]$. In the pediatric group, mixed results were reported and at least one study found that OUES determined at different WRs differed significantly within patients with cystic fibrosis and correlated only moderately with $\dot{V}_{\mathrm{O}_{2}}$ peak and VT [180]. Interestingly, OUES showed to be more sensitive to the effects of training than $\Delta \dot{V}_{\mathrm{E}} / \Delta \dot{V}_{\mathrm{CO}_{2}}$ slope in patients with CHF [96], a finding correlated with enhanced cerebral and muscle hemodynamics in another study [95]. On a single investigation from the group which proposed OUEP, this relationship either on isolation or in combination with oscillatory breathing was prognostically superior to traditional key CPET parameters in CHF [89]. Predicting equations for OUES and OUEP have been recently published [169].

\subsection{Postexercise $\dot{V}_{\mathrm{O}_{2}}$}

2.4.1. Physiological Background. After ramp-incremental exercise, $\dot{V}_{\mathrm{O}_{2}}$ does not decline immediately towards the resting level. The traditional view is that there would be a "debt payment" of energy deficit contracted at the start of effort $\left(\mathrm{O}_{2}\right.$ deficit). Indeed, the time course of $\dot{V}_{\mathrm{O}_{2}}$ recovery after a moderate, constant test has been found to track the rate of phosphocreatine resynthesis [181]. At early recovery, replenishment of local $\mathrm{O}_{2}$ sources in muscles (oxymyoglobin and dissolved $\mathrm{O}_{2}$ ) and reloading of haemoglobin are also needed [182]. At later stages, lactate metabolism (oxidation or gluconeogenesis) and increased cathecolamines and temperature also interfere with the dynamics of $\dot{V}_{\mathrm{O}_{2}}$ decrease $[183,184]$.

2.4.2. Technical Considerations. $\dot{V}_{\mathrm{O}_{2}}$ during recovery has been evaluated by (a) the ratio between total $\dot{V}_{\mathrm{O}_{2}}$ during exercise and recovery [185], (b) the time constant of $\dot{V}_{\mathrm{O}_{2}}$ decay (i.e., time to reach $63 \%$ of the lowest value as obtained by fitting a decreasing monoexponential function) [182, 186, 187], (c) $t^{1 / 2}$ (time required for $\dot{V}_{\mathrm{O}_{2}}$ to decrease to half of its peak value) $[185,188-190]$, and (d) $\dot{V}_{\mathrm{O}_{2}} t$-slope (the response slope during the first minute of recovery by linear regression) $[188,189]$. A further increase in $\dot{V}_{\mathrm{O}_{2}}$ during recovery [191] (i.e., a $\dot{V}_{\mathrm{O}_{2}}$ "overshoot") has been found indicative of severe hemodynamic dysfunction as it reflects prolonged $\dot{V}_{\mathrm{O}_{2}}$ kinetics $[192,193]$. Importantly, the level of effort seems not critical for a valid analysis of post-exercise $\dot{V}_{\mathrm{O}_{2}}$ dynamics [190].

2.4.3. Interpretative Issues. Delayed $\dot{V}_{\mathrm{O}_{2}}$ recovery has been related to functional impairment in $\mathrm{CHF}[188,189,192$, 194], myocardial ischemia [195], COPD [196], and functional impairment in several conditions, including cystic fibrosis [197], diabetes [198], deconditioning [199], and obstructive 


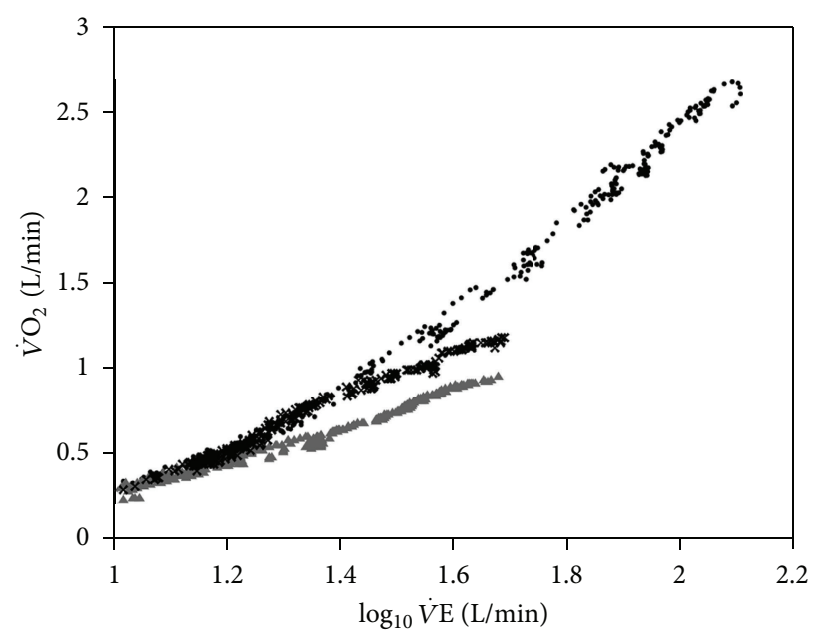

OUES:

$\cdots 2,368 \mathrm{~L} / \mathrm{min} / \log$

$x \times x \times 1,429 \mathrm{~L} / \mathrm{min} / \log$

$\triangle \Delta \triangle 1,013 \mathrm{~L} / \mathrm{min} / \mathrm{log}$

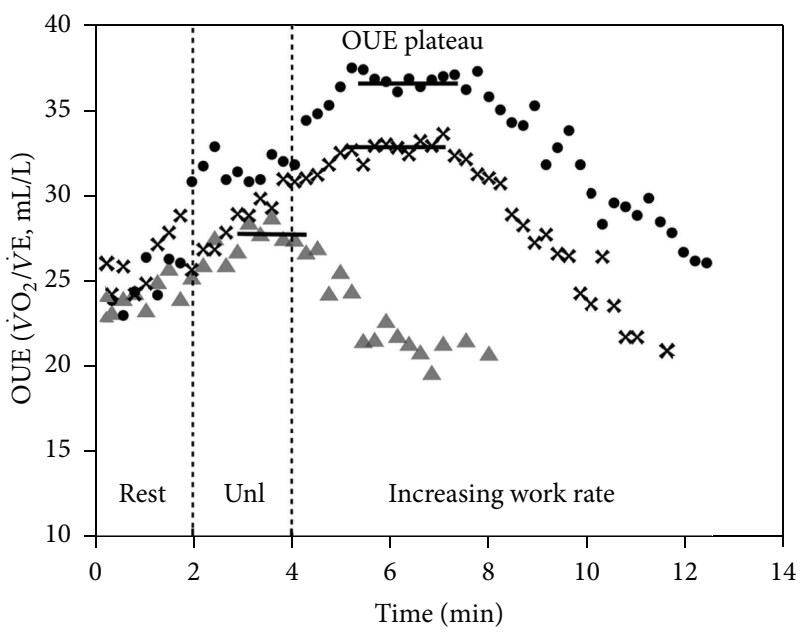

OUEP:

... $36 \mathrm{~mL} / \mathrm{L}$

$x \times x \times 32 \mathrm{~mL} / \mathrm{L}$

$\triangle \Delta \triangle \Delta 28 \mathrm{~mL} / \mathrm{L}$

(a)

(b)

FIGURE 5: Relationship between oxygen uptake $\left(\dot{V}_{\mathrm{O}_{2}}\right)$ and minute ventilation $\left(\dot{V}_{\mathrm{E}}\right)$ during incremental exercise in a healthy subject $(\bullet \bullet \bullet)$ and patients with mild (xxxx) and severe ( $\mathbf{\Lambda} \mathbf{\Lambda} \mathbf{\Delta})$ CHF. (a) The slope of $\dot{V}_{\mathrm{O}_{2}}$ upon $\log _{10} \dot{V}_{\mathrm{E}}$ is the oxygen uptake efficiency slope (OUES) which gives the rate of increase in $\dot{V}_{\mathrm{O}_{2}}$ for a 10-fold rise in $\dot{V}_{\mathrm{E}}$. (b) The highest $\dot{V}_{\mathrm{O}_{2}} / \dot{V}_{\mathrm{E}}$ ratio is the $\dot{V}_{\mathrm{O}_{2}}$ efficiency slope (OUEP) which is the average of values just prior to the estimated lactate threshold. Unl is unloaded pedaling.

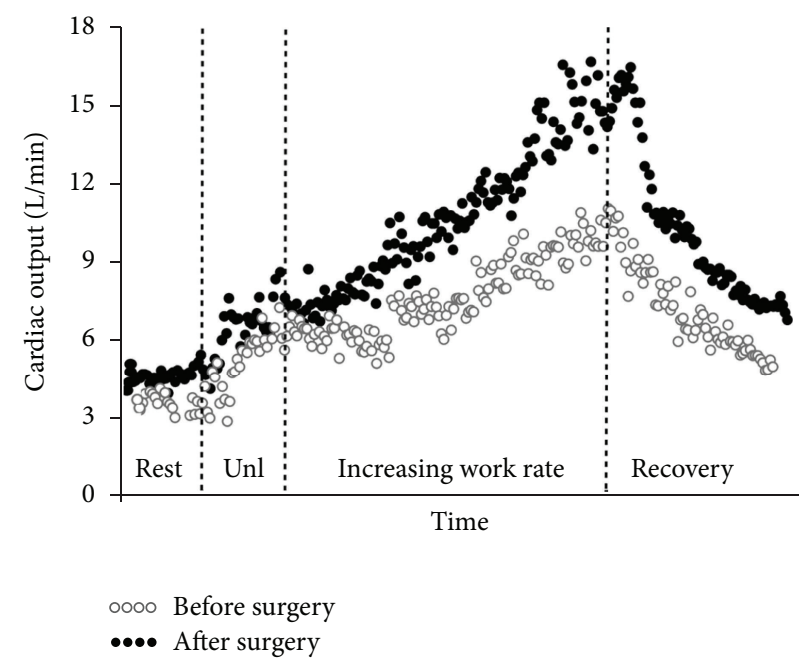

(a)

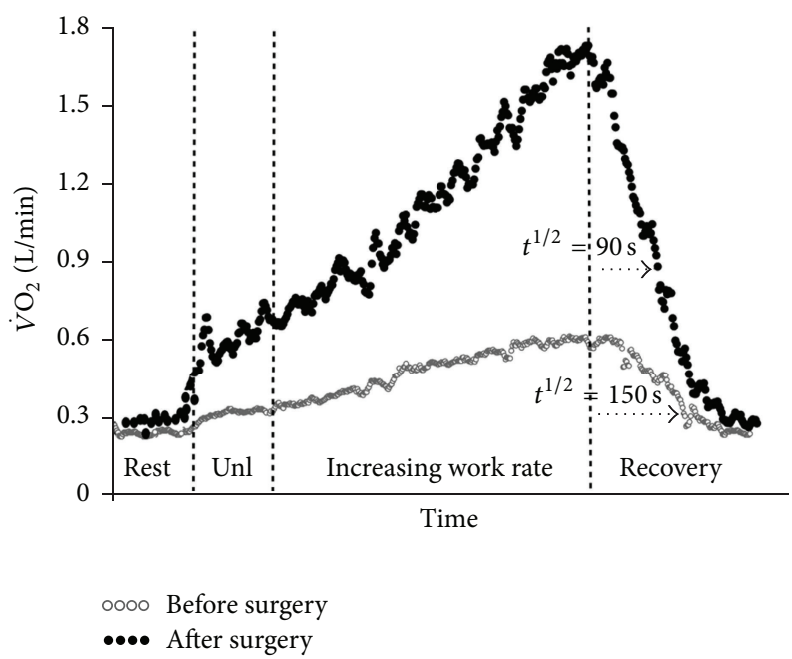

(b)

FiguRE 6: Incremental cycle ergometer exercise tests in the same patient of Figure 4 with chronic thromboembolic pulmonary hypertension. After pulmonary endarterectomy (closed symbols), haemodynamic improvement (panel (a)) led to a higher oxygen uptake $\left(\dot{V}_{\mathrm{O}_{2}}\right)$ at peak exercise and a faster (lower half-time $\left(t^{1 / 2}\right)$ post-exercise decrease in $\dot{V}_{\mathrm{O}_{2}}$ (panel (b)). Cardiac output was noninvasively estimated by impedance cardiography and the tests were time-aligned by total exercise duration. Unl is unloaded pedaling.

sleep apnea [139]. Impairment in cardiovascular responses to exercise as indicated by a delayed recovery of cardiac output was closely associated with slower off-exercise $\dot{V}_{\mathrm{O}_{2}}$ kinetics in $\mathrm{CHF}$ [200]. Improvements in $\mathrm{O}_{2}$ delivery might be expected to speed the rate of $\mathrm{O}_{2}$ recovery in cardiovascular diseases (Figure 6) [201].

\section{Ventilatory Responses}

\subsection{Excess Exercise Ventilation}

3.1.1. Physiological Background. Adequate increases in alveolar ventilation $\left(\dot{V}_{\mathrm{A}}\right)$ are paramount to wash out metabolically 


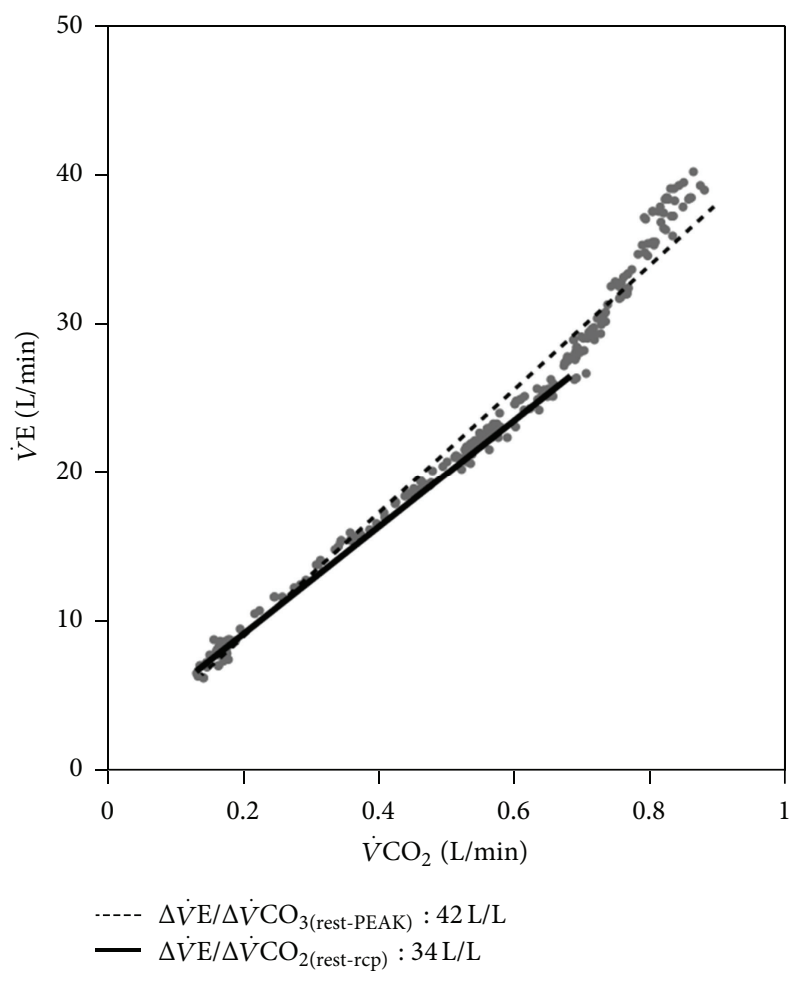

(a)

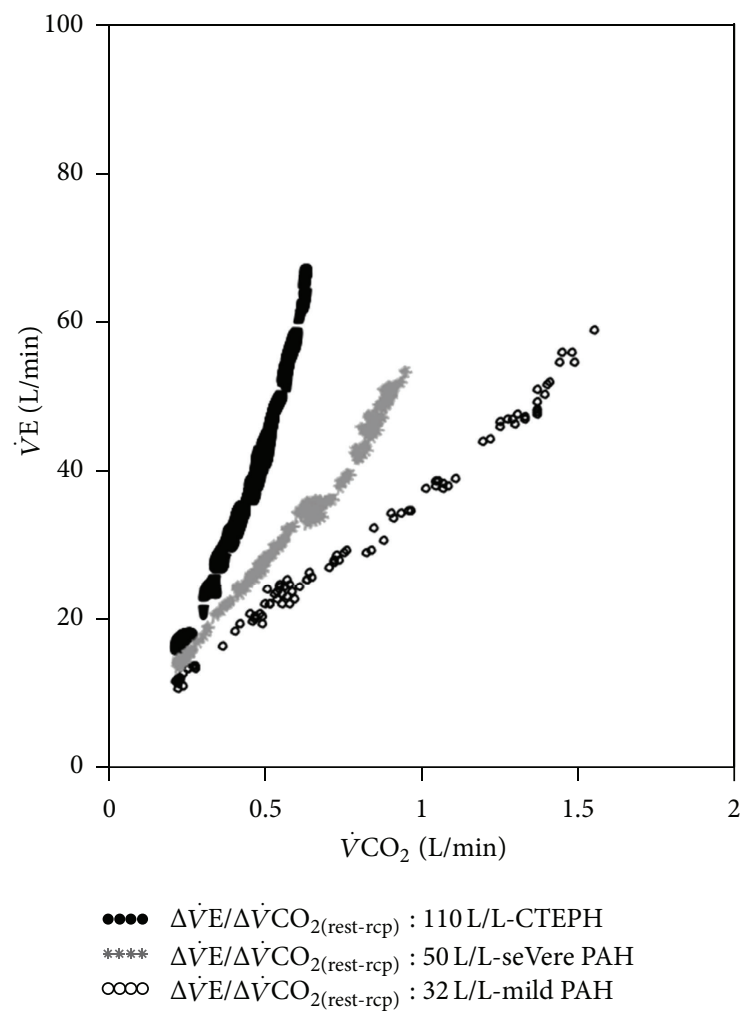

(b)

Figure 7: (a) Minute ventilation $\left(\dot{V}_{\mathrm{E}}\right) /$ carbon dioxide output $\left(\dot{V}_{\mathrm{CO}_{2}}\right)$ relationship from the beginning of exercise to the respiratory compensation point (solid line) or up to peak exercise (dashed line) in a patient with CHF. Note that $\Delta \dot{V}_{\mathrm{E}} / \Delta \dot{V}_{\mathrm{CO}}$ is steeper than $\Delta \dot{V}_{\mathrm{E}} / \Delta \dot{V}_{\mathrm{CO}_{2(\text { rest-RCP) }}}$ because it adds a component of hyperventilation to lactic acidosis and/or other stimuli after the respiratory compensation point. (b) $\Delta \dot{V}_{\mathrm{E}} / \Delta \dot{V}_{\mathrm{CO}_{2}}$ as a function of disease severity in pulmonary arterial hypertension (PAH). Higher values, however, are usually found in chronic thromboembolic pulmonary hypertension $(\mathrm{CTEPH})$ due to pronounced increases in tidal volume ratio. 


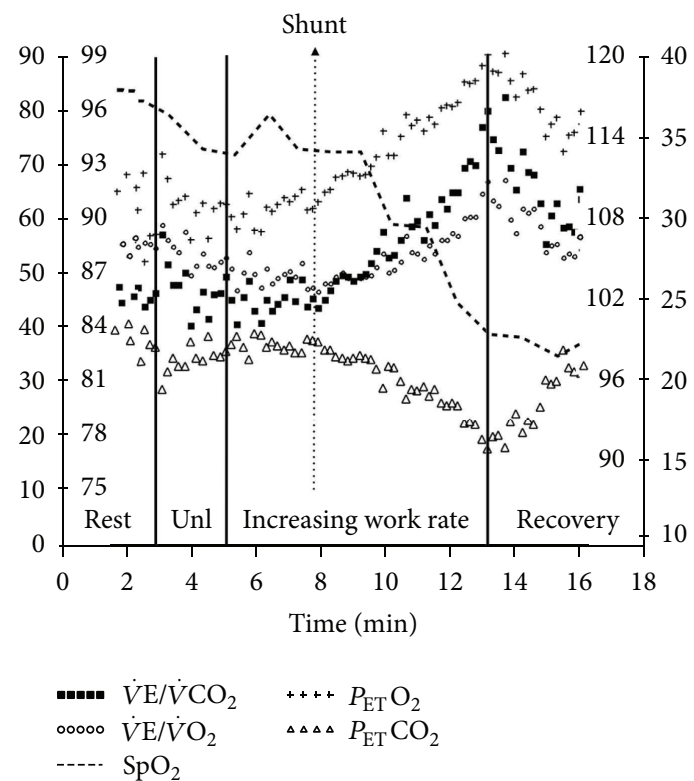

FIGURE 8: Exercise-induced right-to-left shunt as suggested by sudden decrease in oxyhemoglobin saturation by pulse oximetry $\left(\mathrm{SpO}_{2}\right)$ and abrupt increases in the ventilatory equivalents for $\mathrm{CO}_{2}$ and $\mathrm{O}_{2}\left(\dot{V}_{\mathrm{E}} / \dot{V}_{\mathrm{CO}_{2}}\right.$ and $\left.\dot{V}_{\mathrm{E}} / \dot{V}_{\mathrm{O}_{2}}\right)$ associated with a sustained decrease in the end-tidal partial pressure for $\mathrm{CO}_{2}\left(P_{\mathrm{ET}} \mathrm{CO}_{2}\right)$ with a concomitant increase in $\mathrm{P}_{\mathrm{ET}} \mathrm{O}_{2}$ in a patient with pulmonary arterial hypertension. Shunting of systemic venous blood in the arterial circulation stimulated the peripheral chemoreceptors thereby leading to this pattern of ventilatory and gas exchange responses. Unl is unloaded pedaling.

produced $\mathrm{CO}_{2}$. Exercise $\dot{V}_{\mathrm{E}}$ for a given $\dot{V}_{\mathrm{CO}_{2}}$ is inversely related to the prevailing level at which $P_{\mathrm{a}} \mathrm{CO}_{2}$ is regulated (the $\mathrm{CO}_{2}$ "set-point") and the dead space $\left(V_{\mathrm{D}}\right) /$ tidal volume $\left(V_{\mathrm{T}}\right)$ ratio; that is,

$$
\frac{\dot{V}_{\mathrm{E}}}{\dot{V}_{\mathrm{CO}_{2}}}=\frac{1}{P_{\mathrm{a}} \mathrm{CO}_{2}\left(1-\left(V_{\mathrm{D}} / V_{\mathrm{T}}\right)\right)} \text {. }
$$

Consequently, the largest $\dot{V}_{\mathrm{E}} / \dot{V}_{\mathrm{CO}_{2}}$ values will be found in those who chronically hyperventilate (low $\mathrm{CO}_{2}$ "set-point") and have the large $V_{\mathrm{D}}$ coupled with a low $V_{\mathrm{T}}$ [202-206]. In the clinical literature, an increased slope of the $\dot{V}_{\mathrm{E}}-\dot{V}_{\mathrm{CO}_{2}}$ relationship has been termed ventilatory "inefficiency" though it could be argued that there is no "inefficiency" when increased $\dot{V}_{\mathrm{E}}$ results from alveolar hyperventilation. "Excess exercise ventilation" seems therefore a more appropriated description of a greater-than-expected ventilatory response to metabolic demand [205].

3.1.2. Technical Considerations. There are a number of alternatives to express the $\dot{V}_{\mathrm{E}}-\dot{V}_{\mathrm{CO}_{2}}$ relationship during progressive exercise: (1) as a ratio $\left(\dot{V}_{\mathrm{E}} / \dot{V}_{\mathrm{CO}_{2}}\right)$ at peak exercise, at the VT (Figure 1(b)), and as the lowest (nadir) value and (2) as a slope of $\dot{V}_{\mathrm{E}}$ versus $\dot{V}_{\mathrm{CO}_{2}}$ from the beginning of exercise to the RCP $\left(\Delta \dot{V}_{\mathrm{E}} / \Delta \dot{V}_{\left.\mathrm{CO}_{2(\text { rest-RCP) }}\right)}\right.$ (Figure 2(c)) or, alternatively, up to peak exercise $\left(\Delta \dot{V}_{\mathrm{E}} / \Delta \dot{V}_{\left.\mathrm{CO}_{2(\text { rest-PEAK) }}\right)}\right)$ (Figure 7) $[25,26,207]$.
Sun et al. reported that the $\dot{V}_{\mathrm{E}} / \dot{V}_{\mathrm{CO}_{2(\text { nadir) }}}$ had the least variability with the advantage that choosing the lowest value does not require VT identification [26]. However, $\dot{V}_{\mathrm{E}} / \dot{V}_{\mathrm{CO}_{2}}$ might not decline at all during early exercise in some patients with severe cardiopulmonary disease (Figure 8) which might preclude LT identification. $P_{\mathrm{a}} \mathrm{CO}_{2}$ is relatively constant up to the RCP, and, as described (2), a steeper-than-normal $\Delta \dot{V}_{\mathrm{E}} / \Delta \dot{V}_{\mathrm{CO}_{2(\text { (rest-RCP) }}}$ can be explained by a higher $V_{\mathrm{D}} / V_{\mathrm{T}}$ and/or a low $\mathrm{CO}_{2}$ set point. $\Delta \dot{V}_{\mathrm{E}} / \Delta \dot{V}_{\mathrm{CO}_{2 \text { (rest-PEAK) }}}$ is expected to be even steeper than $\Delta \dot{V}_{\mathrm{E}} / \Delta \dot{V}_{\mathrm{CO}_{2 \text { (rest-RCP) }}}$ (Figure 7(a)) because the former adds a component of hyperventilation to lactic acidosis and/or to other sources of $\dot{V}_{\mathrm{E}}$ stimuli at near maximum exercise [26, 207]. It should be emphasized, however, that there are interpretational pitfalls of using $\Delta \dot{V}_{\mathrm{E}} / \Delta \dot{V}_{\mathrm{CO}_{2(\text { rest-PEAK) }}}$ as a single linear characterization of a relationship which is characteristically curvilinear (Figure 7). $\dot{V}_{\mathrm{E}} / \dot{V}_{\mathrm{CO}_{2 \text { nadir }}}$ is equal to $\Delta \dot{V}_{\mathrm{E}} / \Delta \dot{V}_{\mathrm{CO}_{2(\text { rest-RCP) }}}$ when the slope has an $y$-intercept of zero. However, $\Delta \dot{V}_{\mathrm{E}} / \Delta \dot{V}_{\mathrm{CO}_{2(\text { rest-RCP) }}}$ has a positive $y$-intercept in normal subjects [208] which explains why $\dot{V}_{\mathrm{E}} / \dot{V}_{\mathrm{CO}_{2 \mathrm{VT}}}$ is usually greater than the slope. $\dot{V}_{\mathrm{E}} / \dot{V}_{\mathrm{CO}_{2 \mathrm{VT}}}$ will also exceed the slope if the $\mathrm{VT}$ is a low value (i.e., in less fit subjects) [10]. On the other hand, a very steep $\Delta \dot{V}_{\mathrm{E}} / \Delta \dot{V}_{\mathrm{CO}_{2(\text { rest-RCP) }}}$ would produce a negative $y$-intercept thereby making it greater than $\dot{V}_{\mathrm{E}} / \dot{V}_{\mathrm{CO}_{2 \mathrm{VT}}}$ [205].

3.1.3. Interpretative Issues. $\Delta \dot{V}_{\mathrm{E}} / \Delta \dot{V}_{\mathrm{CO}_{2(\text { rest. RCP) }}}$ in healthy young males is approximately $30[25,26]$; however, it increases with age probably as a result of larger $V_{\mathrm{D}} / V_{\mathrm{T}}$ in older subjects $[10,11]$. Females have lower $V_{T}$ for a given $\dot{V}_{\mathrm{E}}$ than males independent of senescence which might explain their higher $\Delta \dot{V}_{\mathrm{E}} / \Delta \dot{V}_{\mathrm{CO}_{2(\text { rest-RCP) }}}$ across all age ranges (Figure 3(c)) [10, 11]. There is plenty of evidence that $\Delta \dot{V}_{\mathrm{E}} / \Delta \dot{V}_{\mathrm{CO}_{2(\text { rest-RCP) }}}$ is clinically useful as a prognostic marker in CHF [52, 108, 109, 163, 209-212] and, more recently, in PAH $[97,98,213]$ with more discriminatory information than $\dot{V}_{\mathrm{O}_{2}}$ peak. The prognostic value in CHF persisted in patients on $\beta$-blockers $[99,100]$. Interestingly, $\Delta \dot{V}_{\mathrm{E}} / \Delta \dot{V}_{\mathrm{CO}_{2(\text { rest-PEAK) }}}$ has been found better than $\Delta \dot{V}_{\mathrm{E}} / \Delta \dot{V}_{\mathrm{CO}_{2(\text { rest-RCP) }}}$ to predict 1-year cardiac mortality and hospitalization in these patients [207]. As expected, composite scores adding $\Delta \dot{V}_{\mathrm{E}} / \Delta \dot{V}_{\mathrm{CO}}$ to other cardiopulmonary variables improved even further their prognostic value [211]. A single study found that coexistence of COPD tends to "normalize" $\Delta \dot{V}_{\mathrm{E}} / \Delta \dot{V}_{\mathrm{CO}_{2}}$ in CHF patients which casts doubt on its prognostic usefulness in this specific subpopulation [214].

In patients with PAH, $\Delta \dot{V}_{\mathrm{E}} / \Delta \dot{V}_{\mathrm{CO}_{2}}$ and $\dot{V}_{\mathrm{E}} / \dot{V}_{\mathrm{CO}_{2}}$ (at rest, VT, and peak) are higher compared to CHF [215]. $\dot{V}_{\mathrm{E}} / \dot{V}_{\mathrm{CO}_{2 \mathrm{VT}}}>37$ plus $P_{\mathrm{ET}} \mathrm{CO}_{2 \mathrm{VT}}<30 \mathrm{mmHg}$ increased the probability of pulmonary vascular disease [111]. In those with idiopathic PAH, higher $\Delta \dot{V}_{\mathrm{E}} / \Delta \dot{V}_{\mathrm{CO}_{2}}$ and $\dot{V}_{\mathrm{E}} / \dot{V}_{\mathrm{CO}_{2}}$ (VT and nadir) were related to clinical [53] and hemodynamic impairment [104]. Importantly, these indexes improved with specific treatment $[104,105]$ and after pulmonary endarterectomy [106]. Although to date there is a lack of evidence that indices 


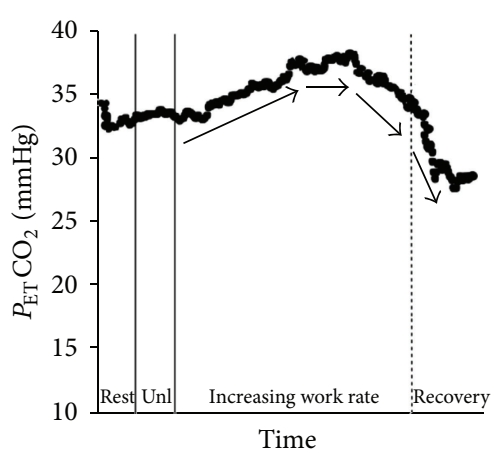

(a)

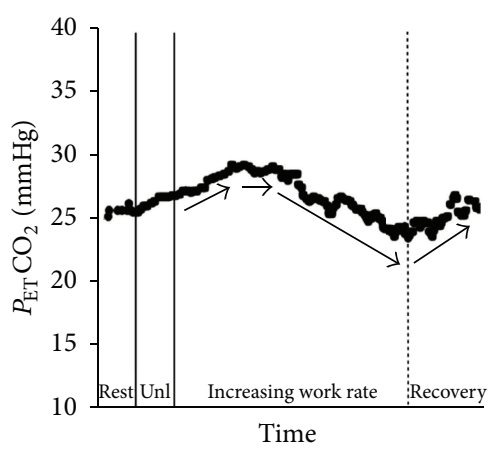

(d)

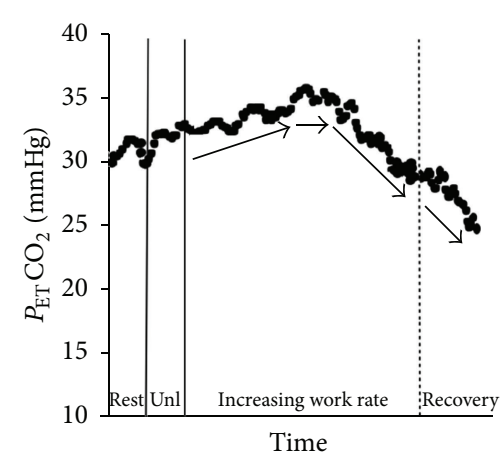

(b)

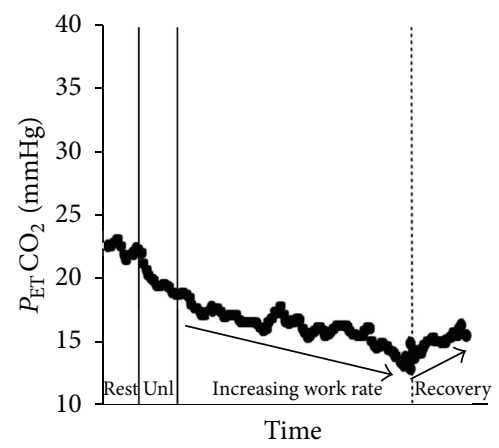

(e)

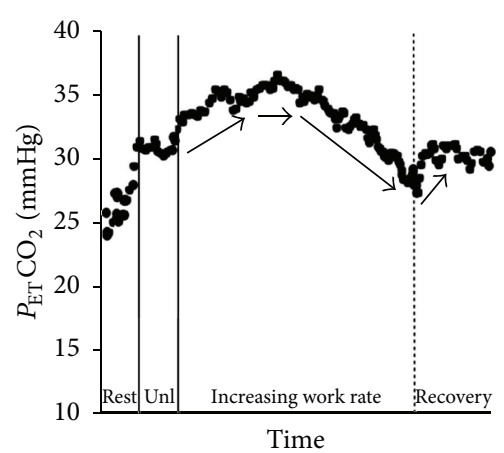

(c)

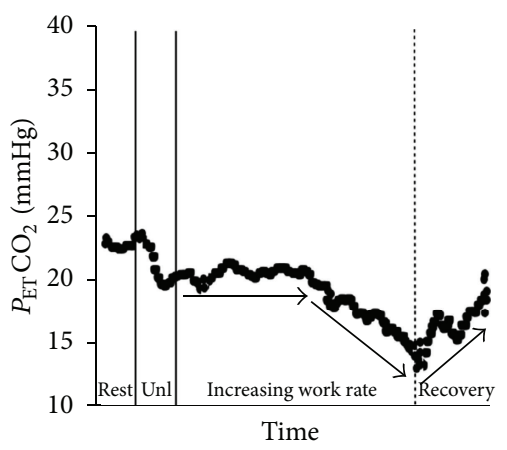

(f)

FIGURE 9: Time course of end-tidal partial pressure for carbon dioxide $\left(P_{\mathrm{ET}} \mathrm{CO}_{2}\right)$ during incremental exercise and early recovery in a healthy control (panel (a)) and five patients with pulmonary arterial hypertension of progressing severity (panels (b) to (f)). Note that $P_{\mathrm{ET}} \mathrm{CO}_{2}$ becomes lower and even fails to increase as disease progresses. Moreover, it frequently increases (instead of diminishing) during recovery. Panel (f), in particular, depicts a severely impaired patient showing abrupt and sustained decrease in $P_{\mathrm{ET}} \mathrm{CO}_{2}$ concomitant with the opening of a forame ovale (Figure 8). Unl is unloaded pedaling.

of excess exercise ventilation in PAH hold the same prognostic importance as in CHF, Deboeck et al. recently described that $\dot{V}_{\mathrm{E}} / \dot{V}_{\mathrm{CO}_{2 \mathrm{VT}}}$ (and the 6-min walking distance) were independent predictors of death [98]. Oudiz et al., however, found that $\dot{V}_{\mathrm{E}} / \dot{V}_{\mathrm{CO}_{2}}$ was valuable to prognosis assessment only when exercise-induced right-to-left shunt (Figure 8) was absent [119]. Although $\dot{V}_{\mathrm{E}} / \dot{V}_{\mathrm{CO}_{2}}$ is particularly disturbed in chronic thromboembolic pulmonary hypertension (CTEPH) (Figure 7(b)), thrombotic vessels occlusion increases $V_{\mathrm{D}} / V_{\mathrm{T}}$ and excess exercise ventilation to levels which may not be proportionately related to hemodynamic impairment [216].

In patients with other chronic respiratory diseases,

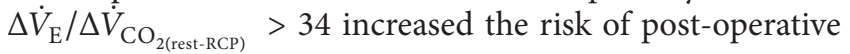
complications after lung resection surgery with better prediction power than $\dot{V}_{\mathrm{O}_{2}}$ peak and predicted post-operative $\dot{V}_{\mathrm{O}_{2}}$ peak [110]. It could also be empirically expected that a low $\dot{V}_{\mathrm{E}} / \dot{V}_{\mathrm{CO}_{2 \mathrm{VT}}}$ would be rarely associated with increased $V_{\mathrm{D}} / V_{\mathrm{T}}$ whereas the opposite would be likely at very high $\dot{V}_{\mathrm{E}} / \dot{V}_{\mathrm{CO}_{2 \mathrm{VT}}}$. In fact, Roman and coworkers recently described that when $\dot{V}_{\mathrm{E}} / \dot{V}_{\mathrm{CO}_{2 V \mathrm{~T}}}$ was $\leq 28$ and within $29-32,96 \%$ and $83 \%$ of subjects had normal $V_{\mathrm{D}} / V_{\mathrm{T}}$. On the other hand, $V_{\mathrm{D}} / V_{\mathrm{T}}$ was abnormal in $87 \%$ of the cases when $\dot{V}_{\mathrm{E}} / \dot{V}_{\mathrm{CO}_{2 \mathrm{VT}}}$ was $\geq 39$. Unfortunately, intermediate values were not useful to dis- criminate the underlying mechanisms. Interestingly, $95 \%$ of the patients with an obstructive ventilatory defect $\left(\mathrm{FEV}_{1} /\right.$ $\mathrm{FVC}<0.7)$ and $\dot{V}_{\mathrm{E}} / \dot{V}_{\mathrm{CO}_{2 V \mathrm{~T}}} \geq 39$ had increased $V_{\mathrm{D}} / V_{\mathrm{T}}[217]$.

\subsection{End-Tidal Partial Pressure for $\mathrm{CO}_{2}$}

3.2.1. Physiological Background. Expired $\mathrm{CO}_{2}$ concentration increases as air from the serial ("anatomic") $V_{\mathrm{D}}$ is progressively enriched with $\mathrm{CO}_{2}$ from the gas exchanging areas. Consequently, the largest partial pressures for $\mathrm{CO}_{2}$ are found at the end of tidal expiration $\left(P_{\mathrm{ET}} \mathrm{CO}_{2}\right)$. However, $P_{\mathrm{ET}} \mathrm{CO}_{2}$ is influenced not only by the metabolic rate (i.e., the rate of increase in mixed venous $P_{\mathrm{CO}_{2}}$ ) but also by the deepness of the previous inspiration (i.e., VT) and the duration of the exhalation. $P_{\mathrm{ET}} \mathrm{CO}_{2}$ reflects poorly $P_{\mathrm{a}} \mathrm{CO}_{2}$, (ideal alveolar) as there are significant regional variations in alveolar $P_{\mathrm{CO}_{2}}\left(P_{\mathrm{A}} \mathrm{CO}_{2}\right)$ and $\dot{V}_{\mathrm{A}}$-to-perfusion ratios-even in normal subjects $[2,16]$. It should also be recognized that $P_{\mathrm{ET}} \mathrm{CO}_{2}$ becomes systematically greater than $P_{\mathrm{a}} \mathrm{CO}_{2}$ during incremental exercise as the first is the peak of the intrabreath oscillation of $P_{\mathrm{A}} \mathrm{CO}_{2}$ and $P_{\mathrm{a}} \mathrm{CO}_{2}$ measured in peripheral arterial blood is an average of the oscillation over several breaths $[2,16]$. 


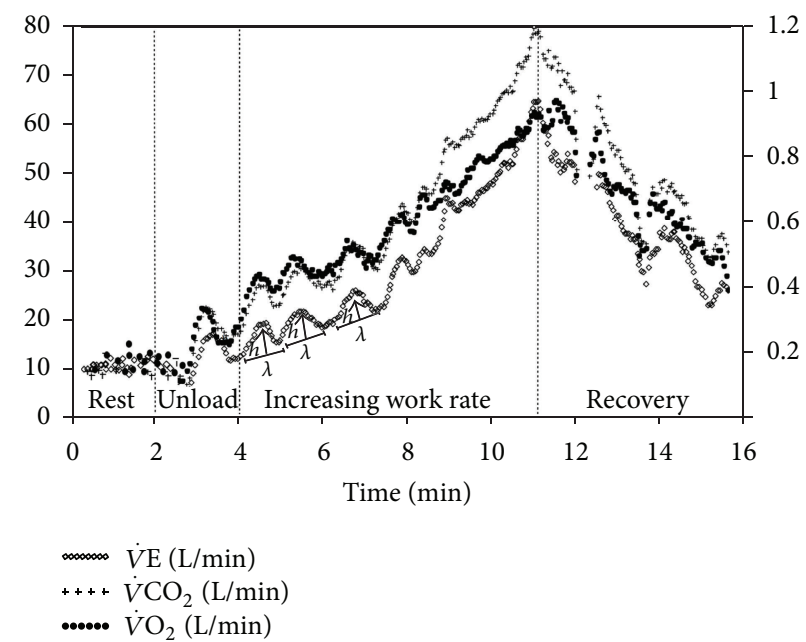

Figure 10: Exertional oscillatory ventilation (EOV) during incremental CPET in a 56-yr-old male with severe CHF. EOV was defined by regular (standard deviation of three consecutive cycle lenghts $(\lambda)$ within $20 \%$ of their average) and ample (minimal $h$ of $5 \mathrm{~L} / \mathrm{min}$ ) cycles of ventilatory $\left(\dot{V}_{\mathrm{E}}\right)$ oscillations [27]. A similar oscillatory pattern is also seen in oxygen uptake $\left(\dot{V}_{\mathrm{O}_{2}}\right)$ and carbon dioxide output $\left(\dot{V}_{\mathrm{CO}_{2}}\right)$.

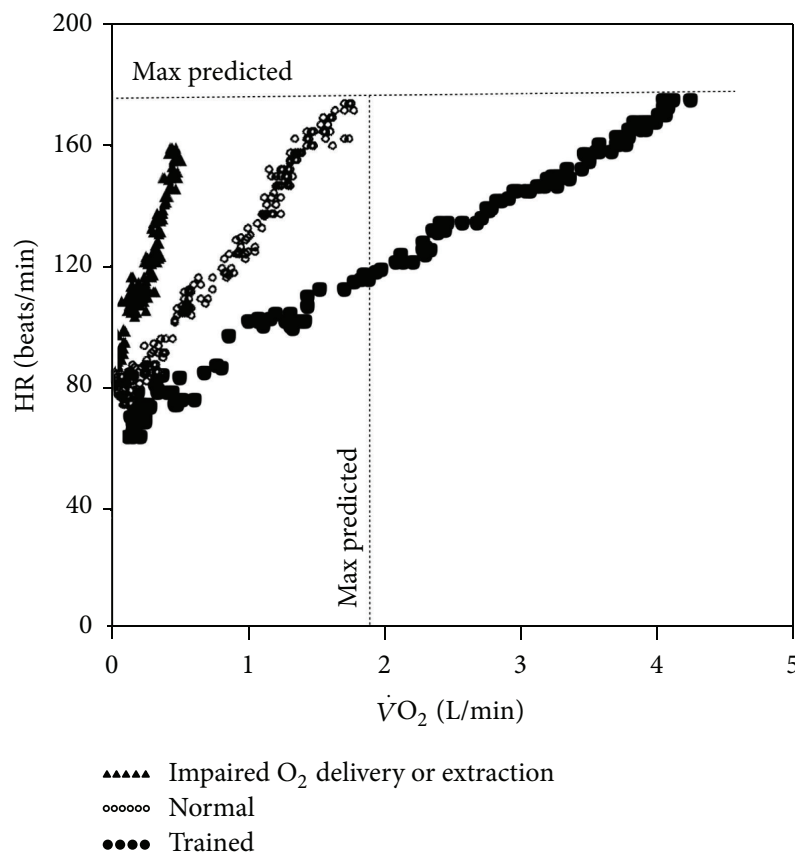

FIGURE 11: Heart rate (HR) response as a function of $\mathrm{O}_{2}$ uptake $\left(\dot{V}_{\mathrm{O}_{2}}\right)$ in 3 males of same age: a patient with abnormal $\mathrm{O}_{2}$ delivery and/or extraction (severe pulmonary arterial hypertension, $\Delta \mathrm{HR} / \Delta \dot{V}_{\mathrm{O}_{2}}=$ 158 beats/L), a normal sedentary subject $\left(\Delta \mathrm{HR} / \Delta \dot{V}_{\mathrm{O}_{2}}=65\right.$ beats/L), and a triathlete $\left(\Delta \mathrm{HR} / \Delta \dot{V}_{\mathrm{O}_{2}}=26\right.$ beats $\left./ \mathrm{L}\right)$.

3.2.2. Technical Considerations. $P_{\mathrm{ET}} \mathrm{CO}_{2}$ increases from rest to LT (which is proportional to decrease in $\dot{V}_{\mathrm{E}} / \dot{V}_{\mathrm{CO}_{2}}$ ) in this time range, followed by a stable phase during the isocapnic buffering period, and then a fall after the RCP (Figures 1(b) and $9(\mathrm{a})$ ). As mentioned, $P_{\mathrm{a}} \mathrm{CO}_{2}$ underestimation by $P_{\mathrm{ET}} \mathrm{CO}_{2}$ is roughly proportional to $V_{\mathrm{D}} / V_{\mathrm{T}}$; consequently, computing $V_{\mathrm{D}} / V_{\mathrm{T}}$ using $P_{\mathrm{ET}} \mathrm{CO}_{2}$ instead of $P_{\mathrm{a}} \mathrm{CO}_{2}$ overestimates $V_{\mathrm{D}} / V_{\mathrm{T}}$ in normal subjects and underestimates it in patients [218].
3.2.3. Interpretative Issues. $P_{\mathrm{ET}} \mathrm{CO}_{2}$ differs from $P_{\mathrm{a}} \mathrm{CO}_{2}$ as a result of ventilation-to-perfusion inhomogeneities, right-toleft shunt, and changes in breathing pattern $[2,16]$. However, arterial blood gases are not routinely measured during clinical CPET. Consequently, interpretation of a reduced $P_{\mathrm{ET}} \mathrm{CO}_{2}$ is complex in the absence of $P_{\mathrm{a}} \mathrm{CO}_{2}$ measurements as it might be related to abnormal gas exchange, alveolar hyperventilation, or a tachypneic and shallow pattern of breathing. Regardless of the exact mechanism, abnormally low values at the LT have been found useful for the diagnosis of pulmonary vascular diseases in patients with unexplained dyspnea [111]. There is now established evidence that $P_{\mathrm{ET}} \mathrm{CO}_{2}$ at rest [112-114], LT [115], and peak exercise [116] are valuable for prognosis estimation and disease severity assessment in CHF $[219,220]$. Low $P_{\mathrm{ET}} \mathrm{CO}_{2}$ values have also been found in $\mathrm{PAH}$ (see also later) $[97,111,117,118]$. Decreased $P_{\mathrm{ET}} \mathrm{CO}_{2}$ at rest and during exercise seems to track the blunted cardiac output response to exercise in cardiovascular disease [219, 221]. Accordingly, exercise training after acute myocardial infarction increases both $P_{\mathrm{ET}} \mathrm{CO}_{2}$ and cardiac output [120]. In addition to reduced cardiac output, an augmented ventilatory drive may also account for a reduction in $P_{\mathrm{ET}} \mathrm{CO}_{2}$ whereas altered breathing pattern seems to have a minor role in $\mathrm{CHF}$ [204].

$P_{\mathrm{ET}} \mathrm{CO}_{2}$ is typically lower in $\mathrm{PAH}$ than $\mathrm{CHF}[111,219]$. In fact, Yasunobu and co-workers suggested that observation of an unusually low $P_{\mathrm{ET}} \mathrm{CO}_{2}$ at the LT $(<30 \mathrm{mmHg}$ or, in particular, $<20 \mathrm{mmHg}$ ) in a patient with exertional dyspnea of unknown cause without evidence of acute hyperventilation (ie, normal R) should prompt the hypothesis of pulmonary vasculopathy [111]. $P_{\mathrm{ET}} \mathrm{CO}_{2}$ response profile is also informative as failure to increase below the LT or progressive decreases from the start of exercise are associated with worsening clinical and hemodynamic impairment (Figures 9(b) to 9(e)) [111] and are rarely found in CHF [112116]. Based on (2), it might be expected that if $P_{\mathrm{ET}} \mathrm{CO}_{2}$ changed parallel to $P_{\mathrm{A}} \mathrm{CO}_{2}$, a hyperbolic relationship between 


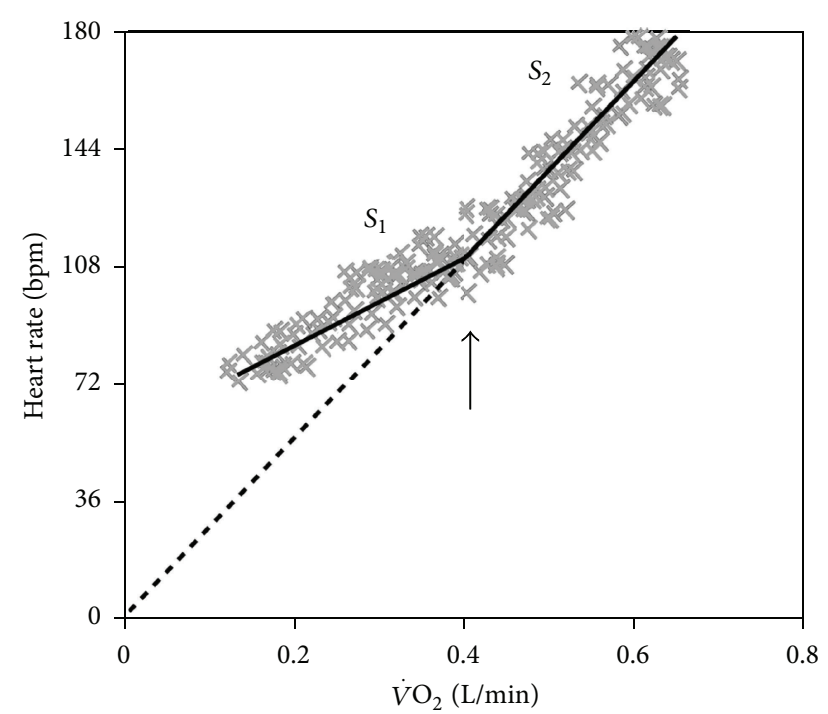

(a)

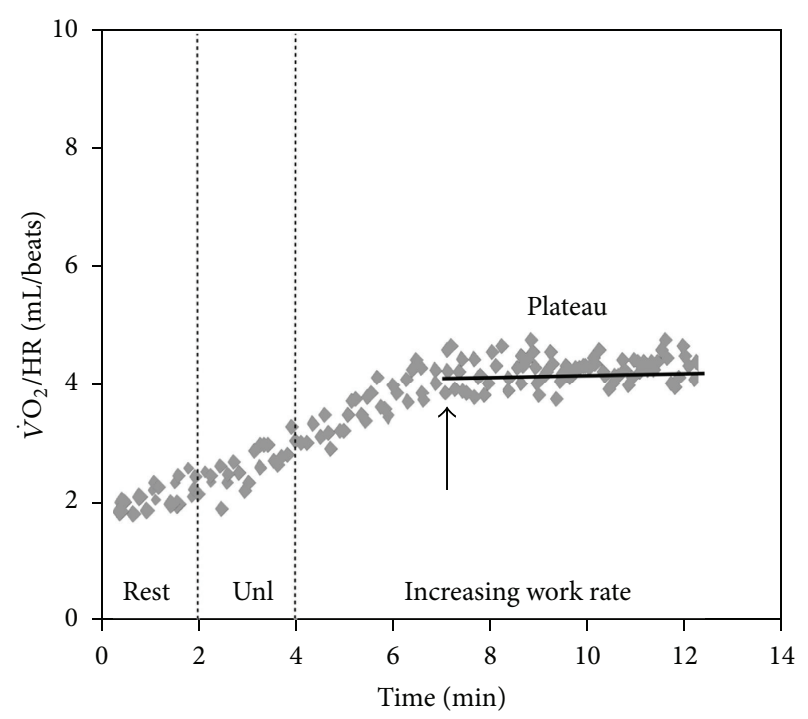

(b)

FIGURE 12: Change in $\Delta$ heart rate $(\mathrm{HR}) / \Delta$ oxygen uptake $\left(\dot{V}_{\mathrm{O}_{2}}\right)$ (arrow) slope (arrow) during incremental CPET in a patient with severe cardiovascular limitation to exercise (panel (a)). Note that this led to a plateau in $\mathrm{O}_{2}$ pulse $\left(\dot{V}_{\mathrm{O}_{2}} / \mathrm{HR}\right.$ ratio) as the $y$-intercept becomes zero; that is, the relationship passes through its origin (panel (b)). Unl is unloaded pedaling.

$\dot{V}_{\mathrm{E}} / \dot{V}_{\mathrm{CO}_{2}}$ and $P_{\mathrm{ET}} \mathrm{CO}_{2}$ at the $\mathrm{LT}$ would result. As this was observed by Yasunobu et al. [111] and confirmed by others $[104,216]$, it seems that alveolar hyperventilation is an important contributing mechanism to the excess exercise ventilation in PAH. Moreover, sharp decreases in $P_{\mathrm{ET}} \mathrm{CO}_{2}$ may indicate exercise-induced intracardiac shunt, a finding with ominous consequences (Figures (8) and 9(f)) [119]. Additionally, an abnormal increase in $P_{\mathrm{ET}} \mathrm{CO}_{2}$ during early recovery has been described in PAH (Figure 9(c)), even in mildly-impaired patients [111].

\subsection{Exertional Oscillatory Ventilation (EOV)}

3.3.1. Physiological Background. An abnormal pattern of ventilation consisting of cyclic hyperpnea and hypopnea without interposed apneas can be detected by CPET in some patients with advanced CHF. The EOV might occur throughout the test, but the oscillations frequently dampen as exercise progresses [121, 222-224]. The pathophysiological mechanisms are multifactorial including low cardiac output leading to a prolonged time of pulmonary venous blood to reach the central or peripheral chemoreceptors, low lung volume, pulmonary congestion, augmented chemoreceptor sensitivity, and the narrow difference between the eupneic $P_{\mathrm{a}} \mathrm{CO}_{2}$ and the apneic (or hypoventilatory) threshold [27, 122, $123,225-235]$.

3.3.2. Technical Considerations. Different criteria for EOV might help explaining why its prevalence has been found to vary from $12 \%$ to $50 \%$ in CHF $[123,124,236-238]$. A widely used definition is as follows (Figure 10): (1) three or more regular oscillations (i.e., clearly discernible from inherent data noise); (2) standard deviation of three consecutive cycle lengths (time between 2 consecutive nadirs) within $20 \%$ of the average; (3) minimal average amplitude of $\dot{V}_{\mathrm{E}}$ oscillation of $5 \mathrm{~L} / \mathrm{min}$ (peak value minus the average of two in-between consecutive nadirs) [27]. Alternative definitions require: (i) criteria for persistence of the EOV pattern (three or more consecutive cyclic oscillations) for at least $60 \%$ of exercise at an amplitude $\geq 15 \%$ of the average resting value $[122,239$ 241] or (ii) 3 or more consecutive cyclic fluctuations with amplitude exceeding $30 \%$ of mean $\dot{V}_{\mathrm{E}}$ and oscillatory cycle within 40 to $140 \mathrm{~s}$ in 3 or more gas exchange/ventilatory variables [124].

3.3.3. Clinical Usefulness. There is now well-established evidence that EOV holds important negative prognostic implications in patients with CHF [27, 124, 222, 236, 239], being related to worsening clinical status [121, 122, 124], severe hemodynamic dysfunction [123], and reduced functional capacity $[125,126]$. Unfortunately, EOV may preclude an adequate identification of the LT by either the $V$-slope or the ventilatory equivalent methods [242]. EOV is highly reproducible regardless of the CHF aetiology [121]. Interestingly, several interventions including inotropics [237], exercise and inspiratory muscle training [243-245], and transplantation [237] lessened of even abolished EOV. Future larger trials should establish whether EOV might add independent information to commonly used outcomes for interventional studies in CHF.

\section{Cardiovascular Responses}

\section{1. $\Delta$ Heart Rate $(H R) / \Delta$ Oxygen Uptake $\left(\dot{V}_{\mathrm{O}_{2}}\right)$}

4.1.1. Physiological Background. Increases in HR with progressive exercise are initially mediated by parasympathetic tonus withdrawal and, subsequently, by increased sympathetic activity [246]. There is an effectively linear increase in 


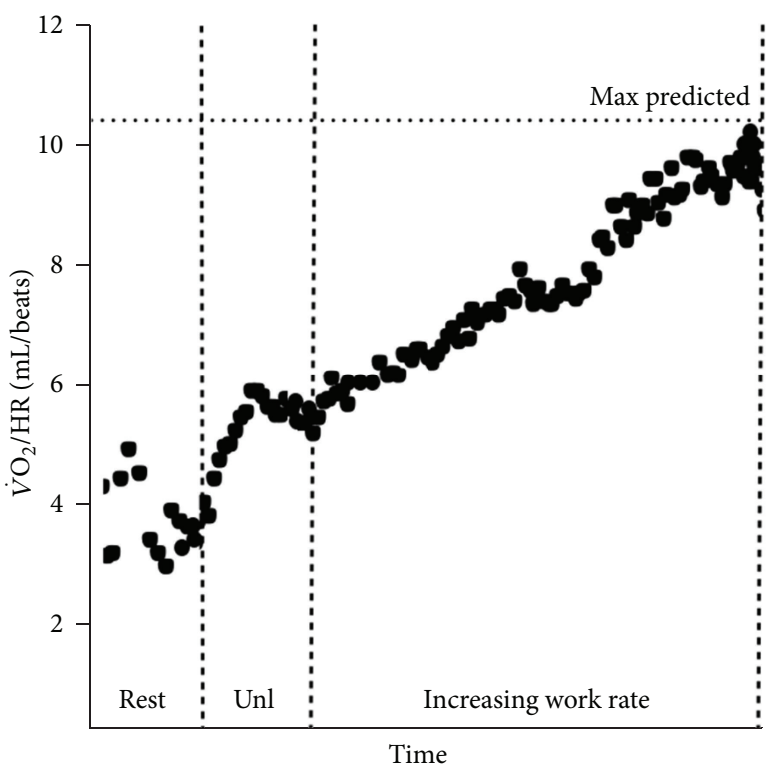

(a)

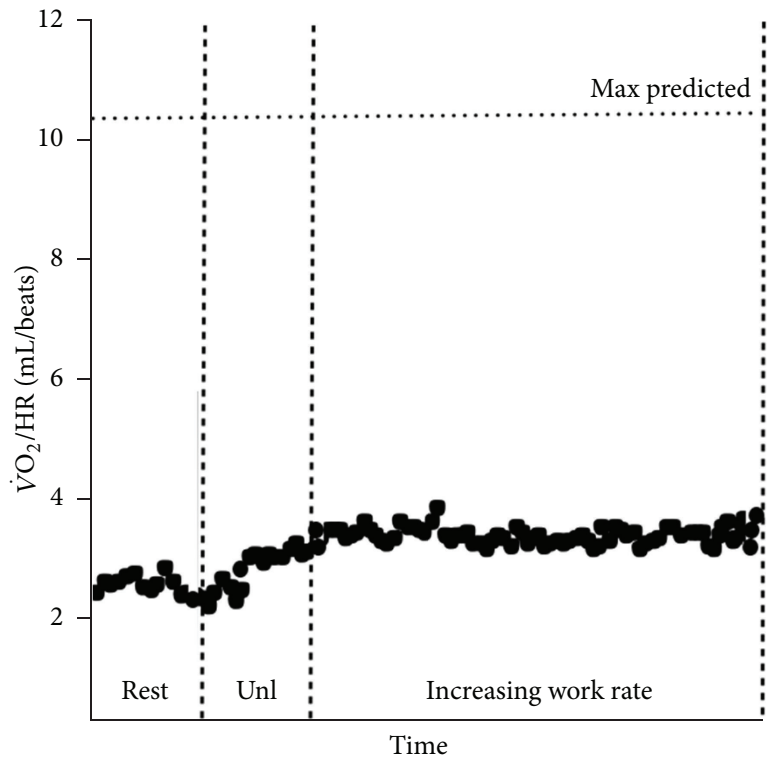

(c)

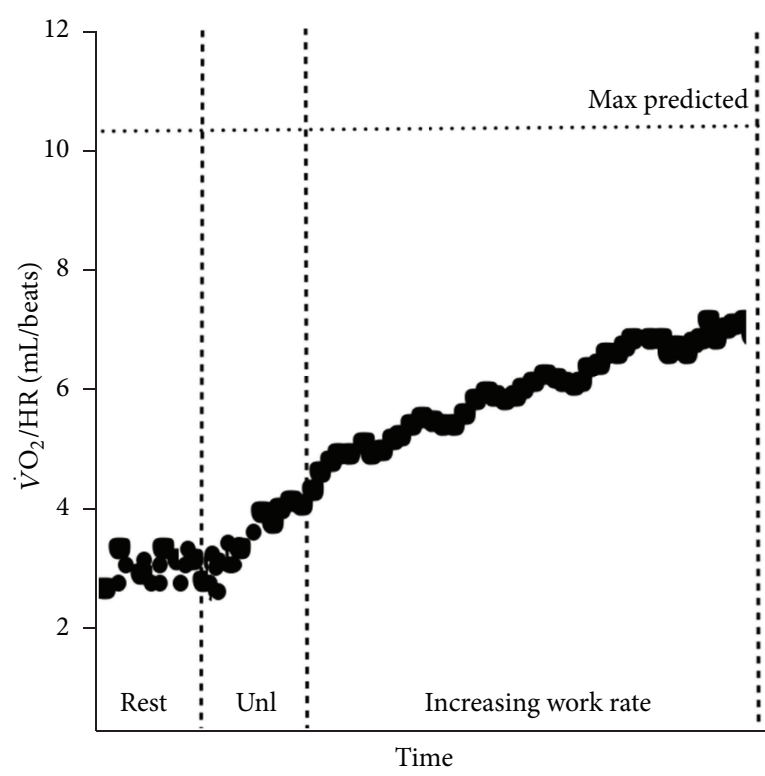

(b)

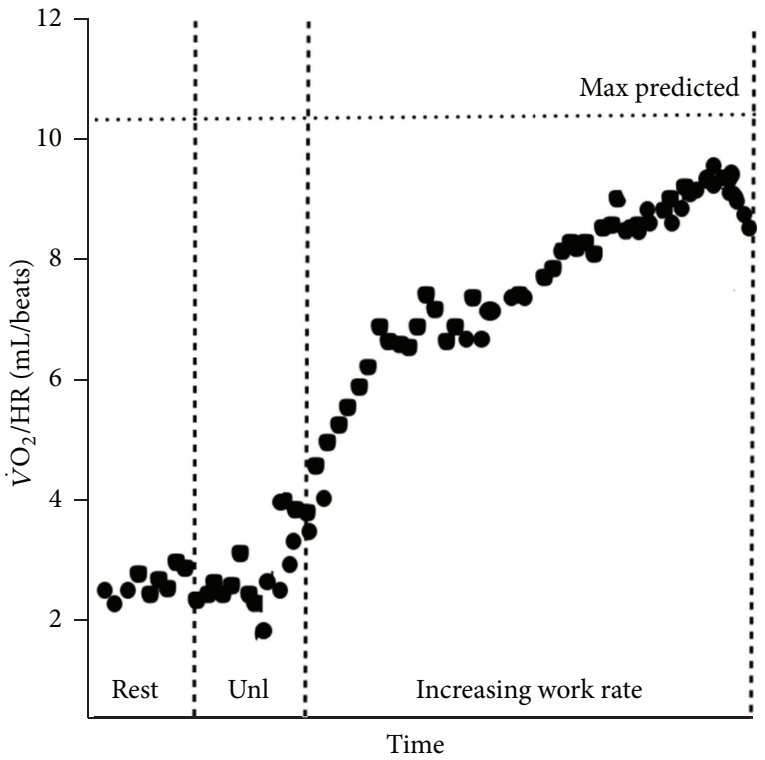

(d)

FIGURE 13: $\mathrm{O}_{2}$ pulse $\left(\dot{V}_{\mathrm{O}_{2}} / \mathrm{HR}\right)$ as a function of time during incremental exercise. (a) Curvilinear increase up to a normal predicted value in a healthy subject; (b) abnormally low peak values due to ventilatory limitation and early exercise cessation in a patient wirh COPD; (c) failure to increase and early plateau in a patient with end-stage pulmonary arterial hypertension; (d) decrease at near maximum exercise in a patients with concomitant electrocardiographic abnormalities indicative of coronary artery disease. Unl is unloaded pedaling.

$\mathrm{HR}$ as a function of $\dot{V}_{\mathrm{O}_{2}}$ during ramp-incremental exercise $[3,24,25]$ though departs from linearity might occur at higher exercise intensities (Figure 2(b)) [247]. According to the Fick principle, reduced stroke volume (SV) and/or diminished $\mathrm{C}(\mathrm{a}-\mathrm{v}) \mathrm{O}_{2}$ would lead to a steeper $\Delta \mathrm{HR} / \Delta \dot{V}_{\mathrm{O}_{2}}$ slope. Consequently, cardiac dysfunction, decreased arterial $\mathrm{O}_{2}$ content (anemia and hypoxemia), and impaired muscle aerobic capacity (e.g., deconditioning, mitochondrial dysfunction) can potentially increase $\Delta \mathrm{HR} / \Delta \dot{V}_{\mathrm{O}_{2}}$. On the other hand, training has a flattening effect on $\Delta \mathrm{HR} / \Delta \dot{V}_{\mathrm{O}_{2}}$ (Figure 11).

4.1.2. Technical Considerations. Although $\dot{V}_{\mathrm{O}_{2}}$ is the appropriate dependent variable, this relationship has been traditionally described with HR on the $y$-axis $[3,24,25]$. Linearity of the HR response throughout the test duration should be firstly established. In event of late departures from linearity, 


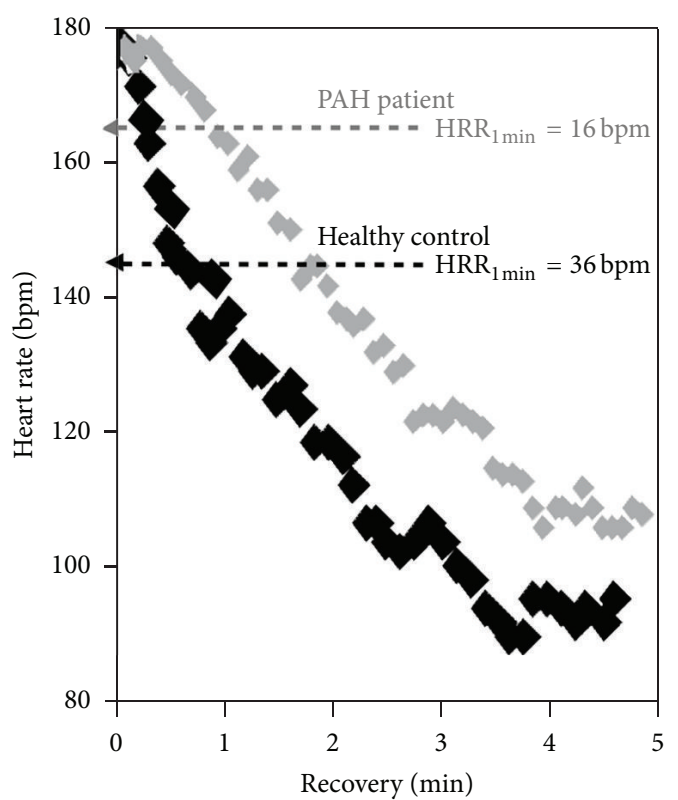

FIGURE 14: Heart rate (HR) response after incremental exercise in a healthy control and a patient with pulmonary arterial hypertension (PAH) of same age and gender (both females aged 31). Note the delayed HR recovery (HRR) up to the 5th minute after-exercise in the patient compared to the control. $\mathrm{HRR}_{1 \mathrm{~min}} \leq 18 \mathrm{bpm}$ after cycle ergometer exercise test has recently been found an independent predictor of mortality in these patients [28].

the slope should be calculated only over the initial linear phase response (Figure 2(b)). As detailed later, pronounced changes in linearity may hold important clinical implications.

4.1.3. Clinical Usefulness. $\Delta \mathrm{HR} / \Delta \dot{V}_{\mathrm{O}_{2}}$ increases with age being consistently higher in females than males (Figure 3(b)) [10]. As expected, cardiovascular and muscular diseases which are known to impair $\mathrm{O}_{2}$ delivery and/or utilization have been found to increase both the slope and the intercept of the $\Delta \mathrm{HR} / \Delta \dot{V}_{\mathrm{O}_{2}}$ relationship [127-130]. Some specific conditions, however, may prevent $\mathrm{HR}$ to increase even in the presence of disease: (a) patients under $\beta$-blocker therapy [248], (b) ischemic involvement of the sinusal node artery [249], and (c) advanced CHF [250]. The so-called $\mathrm{O}_{2}$ pulse $\left(\dot{V}_{\mathrm{O}_{2}} / \mathrm{HR}\right.$ ratio) is a commonly used derivation of $\Delta \mathrm{HR} / \Delta \dot{V}_{\mathrm{O}_{2}}$. As the primary $\dot{V}_{\mathrm{O}_{2}}-\mathrm{HR}$ relationship has a negative $y$-intercept, $\mathrm{O}_{2}$ pulse increases hyperbolically [16] towards an asymptotic value at end-exercise (Figure 13(a)) which might reflect the SV response [131]. However, all pathologic conditions known to increase $\Delta \mathrm{HR} / \Delta \dot{V}_{\mathrm{O}_{2}}$ (including desaturation, anemia, and impaired $\mathrm{O}_{2}$ extraction) will also diminish peak $\mathrm{O}_{2}$ pulse. Moreover, early exercise termination due to symptom limitation (including breathlessness in patients with COPD) (Figure 13(b)) and/or submaximal effort would decrease peak $\mathrm{O}_{2}$ pulse in the absence of cardiovascular limitation. In these cases, however, a normal $\Delta \mathrm{HR} / \Delta \dot{V}_{\mathrm{O}_{2}}$ is reassuring. A more clinically useful pattern of response relates to abrupt increases in $\Delta \mathrm{HR} / \Delta \dot{V}_{\mathrm{O}_{2}}$ slope to an extent that the relationship goes through its origin or becomes with a negative $y$-intercept; that is, $\mathrm{O}_{2}$ pulse turns flat (Figure 12) or even decreases (Figure 13(d)). This suggests that the HR response became the sole mechanism for cardiac output increase due to a severely impaired SV response. In practical grounds, there is limited evidence that as myocardial perfusion is reduced in patients with coronary artery disease, there is reversible left ventricle dysfunction thereby steepening $\Delta \mathrm{HR} / \Delta \dot{V}_{\mathrm{O}_{2}}$ (Figure 12(a)) and flattening (Figure 12(b)) (or even decreasing) (Figure 13(d)) $\mathrm{O}_{2}$ pulse $[88,132,133]$.

\subsection{Heart Rate Recovery (HRR)}

4.2.1. Physiological Background. At the start of exercise, HR increases as a result of early parasympathetic withdrawal and subsequent sympathetic activation [246]. After effort cessation, vagal reactivation (with opposition of the sympathetic drive) is primarily responsible for the return to baseline conditions [251], especially during the first 30 seconds of recovery [252]. Consequently, autonomic imbalance (increased sympathetic stimuli and/or impaired parasympathetic activity) might slow post-exercise HR decay.

4.2.2. Technical Considerations. HRR is the difference between peak HR and HR at selected time points after exercise (e.g., $30 \mathrm{sec}$ and every minute thereafter). HRR analysis may be performed independent of the mode of exercise (treadmill [134, 135, 140, 152, 253], cycle ergometer [28, 254-256], or field tests [257]), and a cool-down period at the end of maximal effort seems not to interfere with its prognostic value $[28,134,150]$.

4.2.3. Interpretative Issues. HRR has been found a simple and inexpensive prognostic marker in healthy populations [134], CHF [135], CAD [151, 258], PAH [28] (Figure 14), diabetes mellitus [136], and COPD [137]. Abnormal HRR has also been demonstrated in other systemic disorders such as metabolic syndrome [138], obstructive sleep apnea [139], sarcoidosis [140], rheumatological diseases [141, 142], polycystic ovary syndrome [143], polycystic kidney disease [144], and HIV infection [145]. Of note, it has been useful for risk stratification in CHF patients with mildly reduced peak $\dot{V}_{\mathrm{O}_{2}}$ [259]. HRR seems to be responsive to exercise training in some disorders [146-149], probably due to effects of exercise on autonomic regulation [260, 261]. Interestingly, these modifications were related to increased survival after rehabilitation in patients with previous myocardial infarction $[262,263]$.

\section{Conclusions}

Interpretation of incremental CPET is best performed by a judicious analysis of all available physiological information provided by the procedure (and by previous testing) taking into consideration the underlying clinical question(s). 
TABLE 1: Clinical usefulness and suggested cutoffs of selected dynamic responses to rapidly incremental CPET.

\begin{tabular}{|c|c|c|}
\hline Variable & Clinical usefulness & Cutoffs/patterns of abnormality \\
\hline \multicolumn{3}{|c|}{ Metabolic } \\
\hline $\begin{array}{l}\text { Estimated lactate } \\
\text { threshold (LT) }\end{array}$ & $\begin{array}{l}\text { (i) Prognosis in CHF [52] } \\
\text { (ii) Marker of disease severity in PAH [53] } \\
\text { (iii) Risk predictor of postoperatory complications in } \\
\text { the elderly [50,51] } \\
\text { (iv) Guide exercise training intensity }[72,73] \\
\text { (v) Responsive to rehabilitation in less impaired } \\
\text { patients with chronic cardiopulmonary diseases }[54,70]\end{array}$ & $\begin{array}{l}\text { (i) } \dot{V}_{\mathrm{O}_{2}} \mathrm{LT}<40 \% \text { predicted } \dot{V}_{\mathrm{O}_{2}} \text { peak }[2] \\
\text { (ii) Influenced by age, gender, and fitness }[4,7,42,76]\end{array}$ \\
\hline $\begin{array}{l}\Delta \dot{V}_{\mathrm{O}_{2}} / \Delta \text { work rate } \\
(\mathrm{mL} / \mathrm{min} / \mathrm{W})\end{array}$ & $\begin{array}{l}\text { (i) Indicative of impaired } \mathrm{O}_{2} \text { delivery and/or utilization } \\
\text { [77-81] } \\
\text { (ii) Adjunct for the diagnosis of myocardial ischemia } \\
\text { [82-88] }\end{array}$ & $\begin{array}{l}\text { (i) }<\text { lower limit of normality }(<8.5 \mathrm{~mL} / \mathrm{min} / \mathrm{W})[4,8] \\
\text { (ii) Decrease in slope (or plateau) as exercise progresses } \\
{[77-81]}\end{array}$ \\
\hline $\begin{array}{l}\dot{V}_{\mathrm{O}_{2}} \text { efficiency slope } \\
\text { (OUES) }\end{array}$ & $\begin{array}{l}\text { (i) Functional impairment and prognosis in CHF } \\
{[18,89-94]} \\
\text { (ii) Response to interventions in CHF [95] } \\
\text { (iii) More sensitive to training than the } \Delta \dot{V}_{\mathrm{E}} / \Delta \dot{V}_{\mathrm{CO}_{2}} \\
\text { slope in CHF [96] }\end{array}$ & $\begin{array}{l}\text { Mortality in CHF } \\
<1.05 \mathrm{~L} / \mathrm{min} / \log (\mathrm{L} / \mathrm{min}) \text { or }<65 \% \text { predicted [89] }\end{array}$ \\
\hline $\begin{array}{l}\dot{V}_{\mathrm{O}_{2}} \text { efficiency plateau } \\
(\mathrm{OUEP})\end{array}$ & Functional impairment and prognosis in CHF [89] & $\begin{array}{l}\text { Mortality in CHF } \\
\quad<25 \mathrm{~mL} / \mathrm{L} \text { or }<65 \% \text { predicted }[89]\end{array}$ \\
\hline \multicolumn{3}{|c|}{ Ventilatory } \\
\hline $\begin{array}{l}\text { Excess exercise } \\
\text { ventilation }\end{array}$ & $\begin{array}{l}\text { (i) Prognosis in PAH }[97,98] \text { and CHF, even under } \\
\beta \text {-blocker therapy (CHF) }[99,100] \\
\text { (ii) Responsive to therapy in CHF [101-103], PAH } \\
{[104,105] \text {, and CTEPH [106] }} \\
\text { (iii) Responsive to exercise training [107] }\end{array}$ & $\begin{array}{l}<\text { age-and gender-specific lower limits of normality } \\
{[10,11]} \\
\text { Mortality in CHF } \\
\Delta \dot{V}_{\mathrm{E}} / \Delta \dot{V}_{\mathrm{CO}_{2} \text { (rest-RCP) }} \geq 34[108] \\
\Delta \dot{V}_{\mathrm{E}} / \Delta \dot{V}_{\mathrm{CO}_{2}(\text { rest-PEAK) }} \geq 45[109] \\
\text { Mortality in PAH } \\
\dot{V}_{\mathrm{E}} / \Delta \dot{V}_{\mathrm{CO}_{2} \text { nadir }} \geq 52[97] \\
\dot{V}_{\mathrm{E}} / \dot{V}_{\mathrm{CO}_{2}} \mathrm{LT} \geq 54[98] \\
\Delta \dot{V}_{\mathrm{E}} / \Delta \dot{V}_{\mathrm{CO}_{2} \text { (rest-RCP) }} \geq 62[98] \\
\Delta \dot{V}_{\mathrm{E}} / \Delta \dot{V}_{\mathrm{CO}_{2} \text { (rest-PEAK) }} \geq 48[97] \\
\text { Postoperative complications of lung resection } \\
\Delta \dot{V}_{\mathrm{E}} / \Delta \dot{V}_{\mathrm{CO}_{2} \text { (rest-RCP) }} \geq 34[110]\end{array}$ \\
\hline $\begin{array}{l}\text { End-tidal partial } \\
\text { pressure for } \mathrm{CO}_{2} \\
\left(P_{\mathrm{ET}} \mathrm{CO}_{2}\right)\end{array}$ & $\begin{array}{l}\text { (i) Adjunct for the diagnosis of PVD [111] } \\
\text { (ii) Prognosis in CHF [112-116] } \\
\text { (iii) Marker of disease severity in PAH [97, 111, 117, 118] } \\
\text { (iv) Diagnosis of a patent forame ovale in PAH [119] } \\
\text { (v) Responsive to drug therapy in PAH[105] and CHF } \\
\text { [101] } \\
\text { (vi) Responsive to exercise training [120] }\end{array}$ & $\begin{array}{l}\text { Diagnosis of PVD [111] } \\
\text { "likely" }=\leq 30 \mathrm{mmHg} \text { at the LT } \\
\text { "very likely" }=\leq 20 \mathrm{mmHg} \text { at the LT } \\
\text { progressive reductions as exercise increases } \\
\text { sudden increase with exercise cessation } \\
\text { Mortality in CHF } \\
\leq 33 \mathrm{mmHg} \text { at rest }[112,114] \\
\leq 36 \mathrm{mmHg} \text { at the LT }[115] \\
<31 \mathrm{mmHg} \text { at peak }[116]\end{array}$ \\
\hline $\begin{array}{l}\text { Exertional oscillatory } \\
\text { ventilation }\end{array}$ & $\begin{array}{l}\text { (i) Indicative of worsening clinical status, severe } \\
\text { hemodynamic dysfunction, and reduced functional } \\
\text { capacity in CHF [121-126] } \\
\text { (ii) Responsive to interventions in CHF [101] }\end{array}$ & $\begin{array}{l}\text { Three or more regular } \dot{V}_{\mathrm{E}} \text { oscillations (standard } \\
\text { deviation of three consecutive cycle lengths within } 20 \% \\
\text { of their average), with minimal average amplitude of } \\
\text { ventilatory oscillation of } 5 \mathrm{~L} / \mathrm{min}[27]\end{array}$ \\
\hline \multicolumn{3}{|c|}{ Cardiovascular } \\
\hline $\begin{array}{l}\Delta \text { Heart rate } / \Delta \dot{V} \mathrm{O}_{2} \\
\text { (beat/L) }\end{array}$ & $\begin{array}{l}\text { (i) Indicative of abnormal cardiovascular response to } \\
\text { exercise }[127-130] \\
\text { (ii) Adjunct for the diagnosis of myocardial ischemia } \\
{[88,131-133]}\end{array}$ & $\begin{array}{l}<\text { age- and gender-specific lower limits of normality } \\
{[9,10]} \\
\text { Changes in linearity with increases in steepness } \\
{[88,132,133]}\end{array}$ \\
\hline
\end{tabular}


TABLE 1: Continued.

\begin{tabular}{|c|c|c|}
\hline Variable & Clinical usefulness & Cutoffs/patterns of abnormality \\
\hline \multirow[t]{7}{*}{$\begin{array}{l}\text { Heart rate recovery } \\
(\mathrm{HRR}) \text { (beats/min) }\end{array}$} & $\begin{array}{l}\text { (i) Prognosis in asymptomatic subjects referred for } \\
\text { exercise testing [134], CHF [135], PAH [28], Type } 2 \\
\text { diabetes [136], and COPD [137] } \\
\text { (ii) Disease severity in metabolic syndrome [138], } \\
\text { obstructive sleep apnea [139], sarcoidosis [140], } \\
\text { rheumatological diseases [141, 142], polycystic ovary } \\
\text { syndrome [143], polycystic kidney disease [144], and } \\
\text { HIV infection [145] } \\
\text { (iii) Responsive to aerobic training in CHF, COPD, } \\
\text { obstructive sleep apnea, and systemic lupus } \\
\text { erythematosus [146-149] }\end{array}$ & $\begin{array}{l}\text { Mortality in patients referred for exercise testing } \\
\text { Treadmill, cooldown: } \\
\qquad \mathrm{HRR}_{1 \text { min }} \leq 12[134,150,151] \\
\text { Treadmill, no cooldown: } \\
\qquad \mathrm{HRR}_{1 \text { min }} \leq 18[135] \\
\mathrm{HRR}_{2 \text { min }} \leq 22[152] \\
\text { Treadmill, no cooldown: } \\
\mathrm{HRR}_{2 \text { min }} \leq 42[153]\end{array}$ \\
\hline & & $\begin{array}{l}\text { Mortality in CHF } \\
\text { Treadmill, cooldown: } \\
\mathrm{HRR}_{1 \mathrm{~min}}<6.5[154]\end{array}$ \\
\hline & & $\begin{array}{l}\text { Treadmill, no cooldown: } \\
\mathrm{HRR}_{1 \text { min }} \leq 12 \text { [155] }\end{array}$ \\
\hline & & $\begin{array}{l}\text { Bike, cooldown: } \\
\mathrm{HRR}_{1 \min }<17[156]\end{array}$ \\
\hline & & $\begin{array}{l}\text { Mortality in PAH } \\
\text { Bike, cooldown: } \\
\mathrm{HRR}_{1 \mathrm{~min}} \leq 18[28]\end{array}$ \\
\hline & & $\begin{array}{l}\text { Mortality in COPD } \\
\text { Bike, cooldown: } \\
\mathrm{HRR}_{1 \mathrm{~min}} \leq 14 \text { [137] }\end{array}$ \\
\hline & & $\begin{array}{l}\text { Mortality in Type } 2 \text { diabetes } \\
\text { Treadmill, cooldown: } \\
\mathrm{HRR}_{1 \text { min }}<12 \\
\mathrm{HRR}_{2 \text { min }}<28[136]\end{array}$ \\
\hline
\end{tabular}

$\dot{V}_{\mathrm{O}_{2}}$ : oxygen uptake; $\dot{V}_{\mathrm{CO}_{2}}$ : carbon dioxide output; $\dot{V}_{\mathrm{E}}$ : minute ventilation; COPD: chronic obstructive pulmonary disease; CHF: chronic heart failure; PAH: pulmonary arterial hypertension; PVD: pulmonary vascular disease; RCP: respiratory compensation point.

Although a considerable lack of information on the individual diagnostic and prognostic value of the dynamic submaximal relationships still persists, the bulk of evidence is reassuring in relation to their practical usefulness. Largescale, multicentric studies, however, are urgently needed to validate the suggested cutoffs of abnormality (Table 1) in different clinical scenarios and disease populations.

\section{Abbreviations}

CAD: Coronary artery disease

CHF: Chronic heart failure

COPD: Chronic obstructive pulmonary disease

CPET: Cardiopulmonary exercise testing

CTEPH: Chronic thromboembolic pulmonary hypertension

EOV: Exertional oscillatory ventilation

$\mathrm{FEV}_{1}$ : Forced expiratory volume in one second

FVC: $\quad$ Forced vital capacity
GET: Gas exchange threshold

HR: Heart rate

HRR: Heart rate recovery

LA: $\quad$ Lactic acid

LT: $\quad$ Lactate threshold

OUES: Oxygen uptake efficiency slope

OUEP: Oxygen uptake efficiency plateau

PAH: Pulmonary arterial hypertension

$P_{\mathrm{a}}: \quad$ Arterial partial pressure

$P_{\mathrm{A}}: \quad$ Alveolar pressure

$P_{\mathrm{ET}}: \quad$ End-tidal partial pressure

PVD: Pulmonary vascular disease

R: Respiratory exchange ratio

RCP: Respiratory compensation point

$\mathrm{SpO}_{2}$ : Pulse oxygen saturation

Unl: Unloaded pedaling

$\dot{V}_{\mathrm{CO}_{2}}$ : Carbon dioxide output

$V_{\mathrm{D}} / V_{\mathrm{T}}$ : Dead space to tidal volume ratio

$\dot{V}_{\mathrm{A}}$ : Alveolar ventilation

$\dot{V}_{\mathrm{E}}: \quad$ Minute ventilation 
$\dot{V}_{\mathrm{E}} / \dot{V}_{\mathrm{O}_{2}}:$ Ventilatory equivalent for $\mathrm{O}_{2}$

$\dot{V}_{\mathrm{E}} / \dot{V}_{\mathrm{CO}_{2}}$ : Ventilatory equivalent for $\mathrm{CO}_{2}$

$\dot{V}_{\mathrm{O}_{2}}: \quad$ Oxygen uptake

VT: $\quad$ Ventilatory threshold

WR: Work rate.

\section{References}

[1] K. Wasserman and B. J. Whipp, "Exercise physiology in health and disease," The American Review of Respiratory Disease, vol. 112, no. 2, pp. 219-249, 1975.

[2] K. Wasserman, J. E. Hansen, D. Y. Sue et al., Principles of Exercise Testing and Interpretation, Lippincott Williams \& Wilkins, Philadelphia, Pa, USA, 5th edition, 2012.

[3] W. L. Beaver, K. Wasserman, and B. J. Whipp, "On-line computer analysis and breath-by-breath graphical display of exercise function tests," Journal of Applied Physiology, vol. 34, no. 1, pp. 128-132, 1973.

[4] B. J. Whipp, J. A. Davis, F. Torres, and K. Wasserman, "A test to determine parameters of aerobic function during exercise," Journal of Applied Physiology Respiratory Environmental and Exercise Physiology, vol. 50, no. 1, pp. 217-221, 1981.

[5] M. J. Buchfuhrer, J. E. Hansen, T. E. Robinson et al., "Optimizing the exercise protocol for cardiopulmonary assessment," Journal of Applied Physiology Respiratory Environmental and Exercise Physiology, vol. 55, no. 5, pp. 1558-1564, 1983.

[6] J. E. Hansen, D. Y. Sue, and K. Wasserman, "Predicted values for clinical exercise testing," The American Review of Respiratory Disease, vol. 129, no. 2, pp. S49-S55, 1984.

[7] B. Koch, C. Schäper, T. Ittermann et al., "Reference values for cardiopulmonary exercise testing in healthy volunteers: the SHIP study," European Respiratory Journal, vol. 33, no. 2, pp. 389-397, 2009.

[8] J. E. Hansen, R. Casaburi, D. M. Cooper, and K. Wasserman, "Oxygen uptake as related to work rate increment during cycle ergometer exercise," European Journal of Applied Physiology and Occupational Physiology, vol. 57, no. 2, pp. 140-145, 1988.

[9] M. S. Fairbarn, S. P. Blackie, N. G. McElvaney, B. R. Wiggs, P. D. Pare, and R. L. Pardy, "Prediction of heart rate and oxygen uptake during incremental and maximal exercise in healthy adults," Chest, vol. 105, no. 5, pp. 1365-1369, 1994.

[10] J. A. Neder, L. E. Nery, C. Peres, and B. J. Whipp, "Reference values for dynamic responses to incremental cycle ergometry in males and females aged 20 to 80," American Journal of Respiratory and Critical Care Medicine, vol. 164, no. 8 I, pp. 14811486, 2001.

[11] X. G. Sun, J. E. Hansen, N. Garatachea, T. W. Storer, and K. Wasserman, "Ventilatory efficiency during exercise in healthy subjects," American Journal of Respiratory and Critical Care Medicine, vol. 166, no. 11, pp. 1443-1448, 2002.

[12] J. Steinacker and S. A. Ward, The Physiology and Pathophysiology of Exercise Toleranceedition, Plenum Press, New York, NY, USA, 1st edition, 1984.

[13] I. M. Weisman, D. Marciniuk, and F. J. Martinez, "ATS/ACCP Statement on cardiopulmonary exercise testing," American Journal of Respiratory and Critical Care Medicine, vol. 167, no. 2, pp. 211-277, 2003.

[14] P. Palange, S. A. Ward, K. H. Carlsen et al., "Recommendations on the use of exercise testing in clinical practice," European Respiratory Journal, vol. 29, no. 1, pp. 185-209, 2007.
[15] B. J. Whipp, P. D. Wagner, and A. Agusti, "Factors determining the response to exercise in healthy subjects," European Respiratory Monograph, vol. 2, no. 6, pp. 3-31, 1997.

[16] B. J. Whipp and P. D. Wagner A, "Determinants of the physiological systems responses to muscular exercise in healthy subjects," in Clinical Exercise Testing, S. A. Ward, P. Palange, and A. Agusti, Eds., vol. 36, pp. 1-35, European Respiratory Monograph, 2007.

[17] S. A. Ward, "Discriminating features of responses in cardiopulmonary exercise testing," in Clinical Exercise Testing, S. A. Ward and P. Palange, Eds., vol. 36, pp. 36-68, European Respiratory Monograph, 2007.

[18] S. Grant, J. McMurray, T. Aitchison et al., "The reproducibility of symptoms during a submaximal exercise test in chronic heart failure," British Journal of Clinical Pharmacology, vol. 45, no. 3, pp. 287-290, 1998.

[19] A. Kettner, A. Goldberg, and J. Hagberg, "Cardiovascular and metabolic responses to submaximal exercise in hemodialysis patients," Kidney International, vol. 26, no. 1, pp. 66-71, 1984.

[20] D. P. Lipkin, J. Bayliss, and P. A. Poole-Wilson, “The ability of a submaximal exercise test to predict maximal exercise capacity in patients with heart failure," European Heart Journal, vol. 6, no. 10 , pp. 829-833, 1985.

[21] A. L. Clark, D. Rafferty, and K. Arbuthnott, "Exercise dynamics at submaximal workloads in patients with chronic heart failure," Journal of Cardiac Failure, vol. 3, no. 1, pp. 15-19, 1997.

[22] R. Belardinelli, Y. Y. Zhang, K. Wasserman, A. Purcaro, and P. G. Agostoni, "A four-minute submaximal constant work rate exercise test to assess cardiovascular functional class in chronic heart failure," The American Journal of Cardiology, vol. 81, no. 10, pp. 1210-1214, 1998.

[23] M. Metra, S. Nodari, D. Raccagni et al., "Maximal and submaximal exercise testing in heart failure," Journal of Cardiovascular Pharmacology, vol. 32, no. 1, pp. S36-S45, 1998.

[24] P. Faggiano and A. Gualeni, "Methodology of exercise test in patients with heart failure. Maximal test and submaximal test," Italian Heart Journal, vol. 1, pp. 313-319, 2000.

[25] V. Bittner, "Exercise testing in heart failure: maximal, submaximal, or both?" Journal of the American College of Cardiology, vol. 42, no. 1, pp. 123-125, 2003.

[26] P. R. Woods, K. R. Bailey, C. M. Wood, and B. D. Johnson, "Submaximal exercise gas exchange is an important prognostic tool to predict adverse outcomes in heart failure," European Journal of Heart Failure, vol. 13, no. 3, pp. 303-310, 2011.

[27] J. J. Leite, A. J. Mansur, H. F. G. De Freitas et al., "Periodic breathing during incremental exercise predicts mortality in patients with chronic heart failure evaluated for cardiac transplantation," Journal of the American College of Cardiology, vol. 41, no. 12, pp. 2175-2181, 2003.

[28] R. P. Ramos, J. S. Arakaki, P. Barbosa et al., "Heart rate recovery in pulmonary arterial hypertension: relationship with exercise capacity and prognosis," American Heart Journal, vol. 163, no. 4, pp. 580-588, 2012.

[29] K. Wasserman, B. J. Whipp, S. N. Koyal, and W. L. Beaver, "Anaerobic threshold and respiratory gas exchange during exercise," Journal of Applied Physiology, vol. 35, no. 2, pp. 236243, 1973.

[30] H. J. Green, R. L. Hughson, G. W. Orr, and D. A. Ranney, "Anaerobic threshold, blood lactate, and muscle metabolites in progressive exercise," Journal of Applied Physiology Respiratory Environmental and Exercise Physiology, vol. 54, no. 4, pp. 1032$1038,1983$. 
[31] W. L. Beaver, K. Wasserman, and B. J. Whipp, "Bicarbonate buffering of lactic acid generated during exercise," Journal of Applied Physiology, vol. 60, no. 2, pp. 472-478, 1985.

[32] H. J. Green and R. L. Hughson, "Anaerobic threshold: review of the concept and directions for future research," Medicine and Science in Sports and Exercise, vol. 17, no. 5, pp. 621-624, 1985.

[33] J. G. Hopker, S. A. Jobson, and J. J. Pandit, "Controversies in the physiological basis of the 'anaerobic threshold' and their implications for clinical cardiopulmonary exercise testing," Anaesthesia, vol. 66, no. 2, pp. 111-123, 2011.

[34] K. Wasserman, W. L. Beaver, and B. J. Whipp, "Gas exchange theory and the lactic acidosis (anaerobic) threshold," Circulation, vol. 81, supplement 1, pp. II14-II30, 1990.

[35] K. Wasserman and A. Koike, "Is the anaerobic threshold truly anaerobic?" Chest, vol. 101, supplement 5, pp. 211S-218S, 1992.

[36] G. A. Brooks, "Current concepts in lactate exchange," Medicine and Science in Sports and Exercise, vol. 23, no. 8, pp. 895-906, 1991.

[37] W. L. Beaver, K. Wasserman, and B. J. Whipp, "A new method for detecting anaerobic threshold by gas exchange," Journal of Applied Physiology, vol. 60, no. 6, pp. 2020-2027, 1986.

[38] U. Reinhard, P. H. Muller, and R. M. Schmulling, "Determination of anaerobic threshold by the ventilation equivalent in normal individuals," Respiration, vol. 38, no. 1, pp. 36-42, 1979.

[39] S. A. Ward, B. J. Whipp, S. Koyal, and K. Wasserman, "Influence of body $\mathrm{CO}_{2}$ stores on ventilatory dynamics during exercise," Journal of Applied Physiology Respiratory Environmental and Exercise Physiology, vol. 55, no. 3, pp. 742-749, 1983.

[40] O. Ozcelik, S. A. Ward, and B. J. Whipp, "Effect of altered body $\mathrm{CO}_{2}$ stores on pulmonary gas exchange dynamics during incremental exercise in humans," Experimental Physiology, vol. 84, no. 5, pp. 999-1011, 1999.

[41] B. J. Whipp, "Mechanisms dissociating pulmonary $\mathrm{CO}_{2}$ and $\mathrm{O}_{2}$ exchange dynamics during exercise," Experimental Physiology, vol. 92, no. 2, pp. 347-355, 2007.

[42] J. A. Neder, L. E. Nery, A. Castelo et al., "Prediction of metabolic and cardiopulmonary responses to maximum cycle ergometry: a randomised study," European Respiratory Journal, vol. 14, no. 6, pp. 1304-1313, 1999.

[43] K. Wasserman, "The anaerobic threshold measurement to evaluate exercise performance," The American Review of Respiratory Disease, vol. 129, no. 2, pp. S35-S40, 1984.

[44] K. Wasserman, "Determinants and detection of anaerobic threshold and consequences of exercise above it," Circulation, vol. 76, no. 6, pp. I-29-I-39, 1987.

[45] K. Wasserman, "The anaerobic threshold: definition, physiological significance and identification," Advances in Cardiology, vol. 35, no. 1, pp. 1-23.

[46] K. Wasserman, "Reduced aerobic enzyme activity in skeletal muscles of patients with heart failure. A prelimary defect or a result of limited cardiac output?" Circulation, vol. 84, no. 4, pp. 1868-1870, 1991.

[47] M. J. Sullivan and F. R. Cobb, "The anaerobic threshold in chronic heart failure. Relation to blood lactate, ventilatory basis, reproducibility, and response to exercise training," Circulation, vol. 81, no. 1, pp. II47-II58, 1990.

[48] M. J. Sullivan, H. J. Green, and F. R. Cobb, "Altered skeletal muscle metabolic response to exercise in chronic heart failure. Relation to skeletal muscle aerobic enzyme activity," Circulation, vol. 84 , no. 4, pp. 1597-1607, 1991.
[49] A. Koike, M. Hiroe, H. Adachi et al., "Anaerobic metabolism as an indicator of aerobic function during exercise in cardiac patients," Journal of the American College of Cardiology, vol. 20, no. 1, pp. 120-126, 1992.

[50] P. Older, R. Smith, P. Courtney, and R. Hone, "Preoperative evaluation of cardiac failure and ischemia in elderly patients by cardiopulmonary exercise testing," Chest, vol. 104, no. 3, pp. 701704, 1993.

[51] P. Older, A. Hall, and R. Hader, "Cardiopulmonary exercise testing as a screening test for perioperative management of major surgery in the elderly," Chest, vol. 116, no. 2, pp. 355-362, 1999.

[52] A. K. Gitt, K. Wasserman, C. Kilkowski et al., "Exercise anaerobic threshold and ventilatory efficiency identify heart failure patients for high risk of early death," Circulation, vol. 106, no. 24, pp. 3079-3084, 2002.

[53] X. G. Sun, J. E. Hansen, R. J. Oudiz, and K. Wasserman, "Exercise pathophysiology in patients with primary pulmonary hypertension," Circulation, vol. 104, no. 4, pp. 429-435, 2001.

[54] A. Patessio, M. Carone, F. Ioli, and C. F. Donner, "Ventilatory and metabolic changes as a result of exercise training in COPD patients," Chest, vol. 101, no. 5, pp. 274S-278S, 1992.

[55] R. Casaburi, A. Patessio, F. Ioli, S. Zanaboni, C. F. Donner, and $\mathrm{K}$. Wasserman, "Reductions in exercise lactic acidosis and ventilation as a result of exercise training in patients with obstructive lung disease," The American Review of Respiratory Disease, vol. 143, no. 1, pp. 9-18, 1991.

[56] T. Kavanagh, M. G. Myers, R. S. Baigrie, D. J. Mertens, P. Sawyer, and R. J. Shephard, "Quality of life and cardiorespiratory function in chronic heart failure: effects of 12 months' aerobic training," Heart, vol. 76, no. 1, pp. 42-49, 1996.

[57] R. Belardinelli, D. Georgiou, G. Cianci, and A. Purcaro, "Randomized, controlled trial of long-term moderate exercise training in chronic heart failure: effects on functional capacity, quality of life, and clinical outcome," Circulation, vol. 99, no. 9, pp. 1173-1182, 1999.

[58] M. Gimenez, E. Servera, P. Vergara, J. R. Bach, and J. M. Polu, "Endurance training in patients with chronic obstructive pulmonary disease: a comparison of high versus moderate intensity," Archives of Physical Medicine and Rehabilitation, vol. 81, no. 1, pp. 102-109, 2000.

[59] R. Hambrecht, C. Walther, S. Möbius-Winkler et al., "Percutaneous coronary angioplasty compared with exercise training in patients with stable coronary artery disease: a randomized trial," Circulation, vol. 109, no. 11, pp. 1371-1378, 2004.

[60] M. Klocek, A. Kubinyi, B. Bacior, and K. Kawecka-Jaszcz, "Effect of physical training on quality of life and oxygen consumption in patients with congestive heart failure," International Journal of Cardiology, vol. 103, no. 3, pp. 323-329, 2005.

[61] R. Zainuldin, M. G. Mackey, and J. A. Alison, "Intensity and type of exercise for lower limb endurance training to optimise exercise capacity for people with chronic obstructive pulmonary disease," Cochrane Database of Systematic Reviews, no. 4, Article ID CD008008, 2009.

[62] R. Hambrecht, J. Neibauer, E. Fiehn et al., "Physical training in patients with stable chronic heart failure: effects on cardiorespiratory fitness and ultrastructural abnormalities of leg muscles," Journal of the American College of Cardiology, vol. 25, no. 6, pp. 1239-1249, 1995.

[63] S. A. Desai and R. N. Channick, "Exercise in patients with pulmonary arterial hypertension," Journal of Cardiopulmonary Rehabilitation and Prevention, vol. 28, no. 1, pp. 12-16, 2008. 
[64] D. Mereles, N. Ehlken, S. Kreuscher et al., "Exercise and respiratory training improve exercise capacity and quality of life in patients with severe chronic pulmonary hypertension," Circulation, vol. 114, no. 14, pp. 1482-1489, 2006.

[65] M. Uchi, T. Saji, and T. Harada, "Feasibility of cardiopulmonary rehabilitation in patients with idiopathic pulmonary arterial hypertension treated with intravenous prostacyclin infusion therapy," Journal of Cardiology, vol. 46, no. 5, pp. 183-193, 2005.

[66] E. Grunig, N. Ehlken, A. Ghofrani et al., "Effect of exercise and respiratory training on clinical progression and survival in patients with severe chronic pulmonary hypertension," Respiration, vol. 81, no. 5, pp. 394-401, 2011.

[67] R. Arena, "Exercise testing and training in chronic lung disease and pulmonary arterial hypertension," Progress in Cardiovascular Diseases, vol. 53, no. 6, pp. 454-463, 2011.

[68] E. Grunig, M. Lichtblau, N. Ehlken et al., "Safety and efficacy of exercise training in various forms of pulmonary hypertension," European Respiratory Journal, vol. 40, no. 1, pp. 84-92, 2012.

[69] E. Grunig, F. Maier, N. Ehlken et al., "Exercise training in pulmonary arterial hypertension associated with connective tissue diseases," Arthritis Research and Therapy, vol. 14, no. 3, p. R148, 2012.

[70] R. Casaburi, A. Patessio, F. Ioli, S. Zanaboni, C. F. Donner, and K. Wasserman, "Reductions in exercise lactic acidosis and ventilation as a result of exercise training in patients with obstructive lung disease," The American Review of Respiratory Disease, vol. 143, no. 1, pp. 9-18, 1991.

[71] I. Vogiatzis, G. Terzis, G. Stratakos et al., "Effect of pulmonary rehabilitation on peripheral muscle fiber remodeling in patients with COPD in GOLD stages II to IV," Chest, vol. 140, no. 3, pp. 744-752, 2011.

[72] T. Meyer, G. Görge, B. Schwaab et al., "An alternative approach for exercise prescription and efficacy testing in patients with chronic heart failure: a randomized controlled training study," American Heart Journal, vol. 149, no. 5, pp. 926.el-926.e7, 2005.

[73] D. Curnier, M. Galinier, A. Pathak et al., "Rehabilitation of patients with congestive heart failure with or without $\beta$ blockade therapy," Journal of Cardiac Failure, vol. 7, no. 3, pp. 241-248, 2001.

[74] E. C. Zacarias, J. A. Neder, S. P. Cendom, L. E. Nery, and J. R. Jardim, "Heart rate at the estimated lactate threshold in patients with chronic obstructive pulmonary disease: effects on the target intensity for dynamic exercise training," Journal of Cardiopulmonary Rehabilitation, vol. 20, no. 6, pp. 369-376, 2000.

[75] D. E. O'Donnell, M. McGuire, L. Samis, and K. A. Webb, "General exercise training improves ventilatory and peripheral muscle strength and endurance in chronic airflow limitation," American Journal of Respiratory and Critical Care Medicine, vol. 157, no. 5, pp. 1489-1497, 1998.

[76] O. Inbar, A. Oren, M. Scheinowitz, A. Rotstein, R. Dlin, and R. Casaburi, "Normal cardiopulmonary responses during incremental exercise in 20- to 70-yr-old men," Medicine and Science in Sports and Exercise, vol. 26, no. 5, pp. 538-546, 1994.

[77] J. E. Hansen, D. Y. Sue, A. Oren, and K. Wasserman, "Relation of oxygen uptake to work rate in normal men and men with circulatory disorders," The American Journal of Cardiology, vol. 59, no. 6, pp. 669-674, 1987.

[78] A. C. Solal, J. M. Chabernaud, and R. Gourgon, "Comparison of oxygen uptake during bicycle exercise in patients with chronic heart failure and in normal subjects," Journal of the American College of Cardiology, vol. 16, no. 1, pp. 80-85, 1990.
[79] A. Koike and K. Wasserman, "Effect of acute reduction in oxygen transport on parameters of aerobic function during exercise," Annals of the Academy of Medicine Singapore, vol. 21, no. 1, pp. 14-22, 1992.

[80] S. Jones, P. M. Elliott, S. Sharma, W. J. McKenna, and B. J. Whipp, "Cardiopulmonary responses to exercise in patients with hypertrophic cardiomyopathy," Heart, vol. 80, no. 1, pp. 6067, 1998.

[81] A. C. Gimenes, J. A. Neder, S. dal Corso et al., "Relationship between work rate and oxygen uptake in mitochondrial myopathy during ramp-incremental exercise," Brazilian Journal of Medical and Biological Research, vol. 44, no. 4, pp. 354-360, 2011.

[82] R. Belardinelli, F. Lacalaprice, F. Carle et al., "Exercise-induced myocardial ischaemia detected by cardiopulmonary exercise testing," European Heart Journal, vol. 24, no. 14, pp. 1304-1313, 2003.

[83] J. P. Schmid, "Detection of exercise induced ischaemia: a new role for cardiopulmonary exercise testing," European Heart Journal, vol. 24, no. 14, pp. 1285-1286, 2003.

[84] S. Chaudhry, R. Arena, K. Wasserman et al., "Exercise-induced myocardial ischemia detected by cardiopulmonary exercise testing," The American Journal of Cardiology, vol. 103, no. 5, pp. 615-619, 2009.

[85] M. Bussotti, A. Apostolo, D. Andreini, P. Palermo, M. Contini, and P. Agostoni, "Cardiopulmonary evidence of exerciseinduced silent ischaemia," European Journal of Cardiovascular Prevention and Rehabilitation, vol. 13, no. 2, pp. 249-253, 2006.

[86] G. J. Balady, R. Arena, K. Sietsema et al., "Clinician's guide to cardiopulmonary exercise testing in adults: a scientific statement from the American Heart Association," Circulation, vol. 122, no. 2, pp. 191-225, 2010.

[87] S. Chaudhry, R. A. Arena, J. E. Hansen et al., "The utility of cardiopulmonary exercise testing to detect and track early-stage ischemic heart disease," Mayo Clinic Proceedings, vol. 85, no. 10, pp. 928-932, 2010.

[88] S. Chaudhry, R. Arena, K. Wasserman et al., "The utility of cardiopulmonary exercise testing in the assessment of suspected microvascular ischemia," International Journal of Cardiology, vol. 148, no. 1, pp. e7-e9, 2011.

[89] X. G. Sun, J. E. Hansen, and W. W. Stringer, "Oxygen uptake efficiency plateau best predicts early death in heart failure," Chest, vol. 141, no. 5, pp. 1284-1294, 2012.

[90] L. C. Davies, R. Wensel, P. Georgiadou et al., "Enhanced prognostic value from cardiopulmonary exercise testing in chronic heart failure by non-linear analysis: oxygen uptake efficiency slope," European Heart Journal, vol. 27, no. 6, pp. 684690, 2006.

[91] R. Arena, P. Brubaker, B. Moore, and D. Kitzman, "The oxygen uptake efficiency slope is reduced in older patients with heart failure and a normal ejection fraction," International Journal of Cardiology, vol. 144, no. 1, pp. 101-102, 2010.

[92] R. Arena, J. Myers, J. Abella et al., "Prognostic significance of the oxygen uptake efficiency slope: percent-predicted versus actual value," American Journal of Cardiology, vol. 105, no. 5, pp. 757758, 2010.

[93] S. Antoine-Jonville, A. Pichon, A. Vazir, M. I. Polkey, and M. J. Dayer, "Oxygen uptake efficiency slope, aerobic fitness, and $\mathrm{V}(\mathrm{E})-\mathrm{VCO}_{2}$ slope in heart failure," Medicine and Science in Sports and Exercise, vol. 44, no. 3, pp. 428-434, 2012.

[94] R. Arena, M. Guazzi, J. Myers et al., "The relationship between minute ventilation and oxygen consumption in heart failure: 
comparing peak $\mathrm{VE} / \mathrm{VO}(2)$ and the oxygen uptake efficiency slope," International Journal of Cardiology, vol. 154, no. 3, pp. 384-385, 2012.

[95] T. C. Fu, C. H. Wang, P. S. Lin et al., "Aerobic interval training improves oxygen uptake efficiency by enhancing cerebral and muscular hemodynamics in patients with heart failure," International Journal of Cardiology. In press.

[96] J. Myers, M. Gademan, K. Brunner, W. Kottman, C. Boesch, and P. Dubach, "Effects of high-intensity training on indices of ventilatory efficiency in chronic heart failure," Journal Cardiopulmonary Rehabilitation and Prevention, vol. 32, pp. 9-16, 2012.

[97] H. Groepenhoff, A. Vonk-Noordegraaf, A. Boonstra, M. D. Spreeuwenberg, P. E. Postmus, and H. J. Bogaard, "Exercise testing to estimate survival in pulmonary hypertension," Medicine and Science in Sports and Exercise, vol. 40, no. 10, pp. 1725-1732, 2008.

[98] G. Deboeck, C. Scoditti, S. Huez et al., "Exercise to predict outcome in idiopathic vs associated pulmonary arterial hypertension," European Respiratory Journal, vol. 40, no. 6, pp. 14101419, 2012.

[99] R. A. Arena, M. Guazzi, J. Myers, and J. Abella, “The prognostic value of ventilatory efficiency with beta-blocker therapy in heart failure," Medicine and Science in Sports and Exercise, vol. 39, no. 2, pp. 213-219, 2007.

[100] R. Wolk, B. D. Johnson, V. K. Somers et al., "Effects of $\beta$-blocker therapy on ventilatory responses to exercise in patients with heart failure," Journal of Cardiac Failure, vol. 11, no. 5, pp. 333339, 2005.

[101] P. Agostoni, M. Contini, A. Magini et al., "Carvedilol reduces exercise-induced hyperventilation: a benefit in normoxia and a problem with hypoxia," European Journal of Heart Failure, vol. 8, no. 7, pp. 729-735, 2006.

[102] P. Agostoni, M. Guazzi, M. Bussotti, S. De Vita, and P. Palermo, "Carvedilol reduces the inappropriate increase of ventilation during exercise in heart failure patients," Chest, vol. 122, no. 6, pp. 2062-2067, 2002.

[103] J. Jaussaud, L. Aimable, P. Bordachar et al., "Cardiac resynchronization therapy reduces metaboreflex contribution to the ventilatory response in heart failure population," Cardiology Research and Practice, vol. 2012, Article ID 914071, 6 pages, 2012.

[104] H. Ting, X. G. Sun, M. L. Chuang, D. A. Lewis, J. E. Hansen, and K. Wasserman, "A noninvasive assessment of pulmonary perfusion abnormality in patients with primary pulmonary hypertension," Chest, vol. 119, no. 3, pp. 824-832, 2001.

[105] R. J. Oudiz, G. Roveran, J. E. Hansen, X. G. Sun, and K. Wasserman, "Effect of sildenafil on ventilatory efficiency and exercise tolerance in pulmonary hypertension," European Journal of Heart Failure, vol. 9, no. 9, pp. 917-921, 2007.

[106] H. Matsuda, H. Ogino, K. Minatoya et al., "Long-term recovery of exercise ability after pulmonary endarterectomy for chronic thromboembolic pulmonary hypertension," The Annals of Thoracic Surgery, vol. 82, no. 4, pp. 1338-1343, 2006.

[107] J. Myers, G. Dziekan, U. Goebbels, and P. Dubach, "Influence of high-intensity exercise training on the ventilatory response to exercise in patients with reduced ventricular function," Medicine and Science in Sports and Exercise, vol. 31, no. 7, pp. 929-937, 1999.

[108] T. P. Chua, P. Ponikowski, D. Harrington et al., "Clinical correlates and prognostic significance of the ventilatory response to exercise in chronic heart failure," Journal of the American College of Cardiology, vol. 29, no. 7, pp. 1585-1590, 1997.
[109] R. Arena, J. Myers, J. Abella et al., "Development of a ventilatory classification system in patients with heart failure," Circulation, vol. 115, no. 18, pp. 2410-2417, 2007.

[110] R. Torchio, M. Guglielmo, R. Giardino et al., "Exercise ventilatory inefficiency and mortality in patients with chronic obstructive pulmonary disease undergoing surgery for nonsmall-cell lung cancer," European Journal of Cardio-thoracic Surgery, vol. 38, no. 1, pp. 14-19, 2010.

[111] Y. Yasunobu, R. J. Oudiz, X. G. Sun, J. E. Hansen, and K. Wasserman, "End-tidal $\mathrm{PCO}_{2}$ abnormality and exercise limitation in patients with primary pulmonary hypertension," Chest, vol. 127, no. 5, pp. 1637-1646, 2005.

[112] R. Arena, J. Myers, J. Abella et al., "The partial pressure of resting end-tidal carbon dioxide predicts major cardiac events in patients with systolic heart failure," American Heart Journal, vol. 156, no. 5, pp. 982-988, 2008.

[113] R. Arena, M. A. Peberdy, J. Myers, M. Guazzi, and M. Tevald, "Prognostic value of resting end-tidal carbon dioxide in patients with heart failure," International Journal of Cardiology, vol. 109, no. 3, pp. 351-358, 2006.

[114] R. Arena, M. Guazzi, J. Myers et al., "Prognostic value of capnography during rest and exercise in patients with heart failure," Congestive Heart Failure, vol. 18, no. 6, pp. 302-307, 2012.

[115] R. Arena, M. Guazzi, and J. Myers, "Prognostic value of endtidal carbon dioxide during exercise testing in heart failure," International Journal of Cardiology, vol. 117, no. 1, pp. 103-108, 2007.

[116] M. Hoshimoto-Iwamoto, A. Koike, O. Nagayama et al., "Prognostic value of end-tidal $\mathrm{CO}_{2}$ pressure during exercise in patients with left ventricular dysfunction," Journal of Physiological Sciences, vol. 59, no. 1, pp. 49-55, 2009.

[117] R. Wensel, C. F. Opitz, S. D. Anker et al., "Assessment of survival in patients with primary pulmonary hypertension: importance of cardiopulmonary exercise testing," Circulation, vol. 106, no. 3, pp. 319-324, 2002.

[118] X. G. Sun, J. E. Hansen, R. J. Oudiz, and K. Wasserman, "Gas exchange detection of exercise-induced right-to-left shunt in patients with primary pulmonary hypertension," Circulation, vol. 105, no. 1, pp. 54-60, 2002.

[119] R. J. Oudiz, R. Midde, A. Hovenesyan et al., "Usefulness of rightto-left shunting and poor exercise gas exchange for predicting prognosis in patients with pulmonary arterial hypertension," The American Journal of Cardiology, vol. 105, no. 8, pp. 11861191, 2010.

[120] Y. Eto, A. Koike, A. Matsumoto et al., "Early aerobic training increases end-tidal $\mathrm{CO}_{2}$ pressure during exercise in patients after acute myocardial infarction," Circulation Journal, vol. 68, no. 8, pp. 778-783, 2004.

[121] U. Corrà, A. Giordano, E. Bosimini et al., "Oscillatory ventilation during exercise in patients with chronic heart failure: clinical correlates and prognostic implications," Chest, vol. 121, no. 5, pp. 1572-1580, 2002.

[122] U. Corrà, M. Pistono, A. Mezzani et al., "Sleep and exertional periodic breathing in chronic heart failure: prognostic importance and interdependence," Circulation, vol. 113, no. 1, pp. 4450, 2006.

[123] R. M. Murphy, R. V. Shah, R. Malhotra et al., "Exercise oscillatory ventilation in systolic heart failure: an indicator of impaired hemodynamic response to exercise," Circulation, vol. 124, pp. 1442-1451, 2011. 
[124] X. G. Sun, J. E. Hansen, J. F. Beshai, and K. Wasserman, "Oscillatory breathing and exercise gas exchange abnormalities prognosticate early mortality and morbidity in heart failure," Journal of the American College of Cardiology, vol. 55, no. 17, pp. 1814-1823, 2010.

[125] L. J. Olson, A. M. Arruda-Olson, V. K. Somers, C. G. Scott, and B. D. Johnson, "Exercise oscillatory ventilation: instability of breathing control associated with advanced heart failure," Chest, vol. 133, no. 2, pp. 474-481, 2008.

[126] R. Arena, M. Guazzi, J. Myers et al., "Exercise oscillatory ventilation reflects diminished quality of life and perceived functional capacity in patients with heart failure," International Journal of Cardiology, vol. 153, no. 2, pp. 213-214, 2011.

[127] L. E. Nery, K. Wasserman, and W. French, "Contrasting cardiovascular and respiratory responses to exercise in mitral valve and chronic obstructive pulmonary diseases," Chest, vol. 83, no. 3, pp. 446-453, 1983.

[128] E. C. Munhoz, R. Hollanda, J. P. Vargas et al., "Flattening of oxygen pulse during exercise may detect extensive myocardial ischemia," Medicine and Science in Sports and Exercise, vol. 39, no. 8, pp. 1221-1226, 2007.

[129] R. Belardinelli, F. Lacalaprice, F. Carle et al., "Exercise-induced myocardial ischaemia detected by cardiopulmonary exercise testing," European Heart Journal, vol. 24, no. 14, pp. 1304-1313, 2003.

[130] B. Grassi, S. Porcelli, M. Marzorati et al., "Metabolic myopathies: functional evaluation by analysis of oxygen uptake kinetics," Medicine and Science in Sports and Exercise, vol. 41, no. 12, pp. 2120-2127, 2009.

[131] B. J. Whipp, M. B. Higgenbotham, and F. C. Cobb, "Estimating exercise stroke volume from asymptotic oxygen pulse in humans," Journal of Applied Physiology, vol. 81, no. 6, pp. 26742679, 1996.

[132] O. Inbar, C. Yamin, I. Bar-On, S. Nice, and D. David, "Effects of percutaneous transluminal coronary angioplasty on cardiopulmonary responses during exercise," Journal of Sports Medicine and Physical Fitness, vol. 48, no. 2, pp. 235-245, 2008.

[133] S. Chaudhry, R. Arena, K. Wasserman et al., "Exercise-induced myocardial ischemia detected by cardiopulmonary exercise testing," The American Journal of Cardiology, vol. 103, no. 5, pp. 615-619, 2009.

[134] C. R. Cole, E. H. Blackstone, F. J. Pashkow, C. E. Snader, and M. S. Lauer, "Heart-rate recovery immediately after exercise as a predictor of mortality," The New England Journal of Medicine, vol. 341, no. 18, pp. 1351-1357, 1999.

[135] J. Watanabe, M. Thamilarasan, E. H. Blackstone, J. D. Thomas, and M. S. Lauer, "Heart rate recovery immediately after treadmill exercise and left ventricular systolic dysfunction as predictors of mortality: the case of stress echocardiography," Circulation, vol. 104, no. 16, pp. 1911-1916, 2001.

[136] K. M. Chacko, T. A. Bauer, R. A. Dale, J. A. Dixon, R. W. Schrier, and R. O. Estacio, "Heart rate recovery predicts mortality and cardiovascular events in patients with type 2 diabetes," Medicine and Science in Sports and Exercise, vol. 40, no. 2, pp. 288-295, 2008.

[137] M. Lacasse, F. Maltais, P. Poirier et al., "Post-exercise heart rate recovery and mortality in chronic obstructive pulmonary disease," Respiratory Medicine, vol. 99, no. 7, pp. 877-886, 2005.

[138] C. Spies, C. Otte, A. Kanaya, S. S. Pipkin, N. B. Schiller, and M. A. Whooley, "Association of metabolic syndrome with exercise capacity and heart rate recovery in patients with coronary heart disease in the heart and soul study," The American Journal of Cardiology, vol. 95, no. 10, pp. 1175-1179, 2005.

[139] S. Nanas, D. Sakellariou, S. Kapsimalakou et al., "Heart rate recovery and oxygen kinetics after exercise in obstructive sleep apnea syndrome," Clinical Cardiology, vol. 33, no. 1, pp. 46-51, 2010.

[140] I. Ardic, M. G. Kaya, M. Yarlioglues et al., "Impaired heart rate recovery index in patients with sarcoidosis," Chest, vol. 139, no. 1, pp. 60-68, 2011.

[141] O. Dogdu, M. Yarlioglues, M. G. Kaya et al., "Deterioration of heart rate recovery index in patients with systemic lupus erythematosus," The Journal of Rheumatology, vol. 37, no. 12, pp. 2511-2515, 2010.

[142] E. B. Kaya, S. Okutucu, H. Aksoy et al., "Evaluation of cardiac autonomic functions in patients with ankylosing spondylitis via heart rate recovery and heart rate variability," Clinical Research in Cardiology, vol. 99, no. 12, pp. 803-808, 2010.

[143] G. Tekin, A. Tekin, E. B. Kiliçarslan et al., "Altered autonomic neural control of the cardiovascular system in patients with polycystic ovary syndrome," International Journal of Cardiology, vol. 130, no. 1, pp. 49-55, 2008.

[144] O. Orscelik, I. Kocyigit, O. Baran et al., "Impairment of heart rate recovery index in autosomal-dominant polycystic kidney disease patients without hypertension," Blood Pressure, vol. 21, no. 5, pp. 300-305, 2012.

[145] W. T. Cade, D. N. Reeds, S. Lassa-Claxton et al., "Post-exercise heart rate recovery in HIV-positive individuals on highly active antiretroviral therapy: early indicator of cardiovascular disease?" HIV Medicine, vol. 9, no. 2, pp. 96-100, 2008.

[146] S. Tiukinhoy, N. Beohar, and M. Hsie, "Improvement in heart rate recovery after cardiac rehabilitation," Journal of Cardiopulmonary Rehabilitation, vol. 23, no. 2, pp. 84-87, 2003.

[147] V. V. Georgiopoulou, S. Dimopoulos, D. Sakellariou et al., "Cardiopulmonary rehabilitation enhances heart rate recovery in patients with COPD," Respiratory Care, vol. 57, pp. 2095-2103, 2012.

[148] C. E. Kline, E. P. Crowley, G. B. Ewing et al., "Blunted heart rate recovery is improved following exercise training in overweight adults with obstructive sleep apnea," International Journal of Cardiology. In press.

[149] R. Miossi, F. B. Benatti, A. L. de Sa Pinto et al., "Exercise training counterbalances chronotropic incompetence and delayed heart rate recovery in systemic lupus erythematosus: a randomized trial," Arthritis Care and Research, vol. 64, no. 8, pp. 1159-1166, 2012.

[150] E. O. Nishime, C. R. Cole, E. H. Blackstone, F. J. Pashkow, and M. S. Lauer, "Heart rate recovery and treadmill exercise score as predictors of mortality in patients referred for exercise ECG," The Journal of the American Medical Association, vol. 284, no. 11, pp. 1392-1398, 2000.

[151] D. P. Vivekananthan, E. H. Blackstone, C. E. Pothier, and M. S. Lauer, "Heart rate recovery after exercise is a predictor of mortality, independent of the angiographic severity of coronary disease," Journal of the American College of Cardiology, vol. 42, no. 5, pp. 831-838, 2003.

[152] K. Shetler, R. Marcus, V. F. Froelicher et al., "Heart rate recovery: validation and methodologic issues," Journal of the American College of Cardiology, vol. 38, no. 7, pp. 1980-1987, 2001.

[153] C. R. Cole, J. M. Foody, E. H. Blackstone, and M. S. Lauer, "Heart rate recovery after submaximal exercise testing as a predictor of mortality in a cardiovascularly healthy cohort," Annals of Internal Medicine, vol. 132, no. 7, pp. 552-555, 2000. 
[154] R. Arena, M. Guazzi, J. Myers, and M. A. Peberdy, "Prognostic value of heart rate recovery in patients with heart failure," American Heart Journal, vol. 151, no. 4, pp. 851-e7, 2006.

[155] S. Nanas, M. Anastasiou-Nana, S. Dimopoulos et al., "Early heart rate recovery after exercise predicts mortality in patients with chronic heart failure," International Journal of Cardiology, vol. 110, no. 3, pp. 393-400, 2006.

[156] M. Guazzi, J. Myers, M. A. Peberdy, D. Bensimhon, P. Chase, and R. Arena, "Heart rate recovery predicts sudden cardiac death in heart failure," International Journal of Cardiology, vol. 144, no. 1, pp. 121-123, 2010.

[157] J. E. Hansen, D. Y. Sue, A. Oren, and K. Wasserman, "Relation of oxygen uptake to work rate in normal men and men with circulatory disorders," The American Journal of Cardiology, vol. 59, no. 6, pp. 669-674, 1987.

[158] L. F. Ferreira, S. Koga, and T. J. Barstow, "Dynamics of noninvasively estimated microvascular $\mathrm{O}_{2}$ extraction during ramp exercise," Journal of Applied Physiology, vol. 103, no. 6, pp. 19992004, 2007.

[159] J. Boone, K. Koppo, T. J. Barstow, and J. Bouckaert, "Aerobic fitness, muscle efficiency, and motor unit recruitment during ramp exercise," Medicine and Science in Sports and Exercise, vol. 42, no. 2, pp. 402-408, 2010.

[160] T. J. Barstow, A. M. Jones, P. H. Nguyen, and R. Casaburi, "Influence of muscle fibre type and fitness on the oxygen uptake/power output slope during incremental exercise in humans," Experimental Physiology, vol. 85, no. 1, pp. 109-116, 2000.

[161] J. Myers, A. Salleh, N. Buchanan et al., "Ventilatory mechanisms of exercise intolerance in chronic heart failure," American Heart Journal, vol. 124, no. 3, pp. 710-719, 1992.

[162] M. Piepoli, A. L. Clark, M. Volterrani, S. Adamopoulos, P. Sleight, and A. J. S. Coats, "Contribution of muscle afferents to the hemodynamic, autonomic, and ventilatory responses to exercise in patients with chronic heart failure: effects of physical training," Circulation, vol. 93, no. 5, pp. 940-952, 1996.

[163] P. Ponikowski, D. P. Francis, M. F. Piepoli et al., "Enhanced ventilatory response to exercise in patients with chronic heart failure and preserved exercise tolerance: marker of abnormal cardiorespiratory reflex control and predictor of poor prognosis," Circulation, vol. 103, no. 7, pp. 967-972, 2001.

[164] M. Hollenberg and I. B. Tager, "Oxygen uptake efficiency slope: an index of exercise performance and cardiopulmonary reserve requiring only submaximal exercise," Journal of the American College of Cardiology, vol. 36, no. 1, pp. 194-201, 2000.

[165] R. Baba, M. Nagashima, M. Goto et al., "Oxygen uptake efficiency slope: a new index of cardiorespiratory functional reserve derived from the relation between oxygen uptake and minute ventilation during incremental exercise," Journal of the American College of Cardiology, vol. 28, no. 6, pp. 1567-1572, 1996.

[166] R. Baba, K. Tsuyuki, Y. Kimura et al., "Oxygen uptake efficiency slope as a useful measure of cardiorespiratory functional reserve in adult cardiac patients," European Journal of Applied Physiology and Occupational Physiology, vol. 80, no. 5, pp. 397-401, 1999.

[167] R. Baba, M. Nagashima, Y. Nagano, M. Ikoma, and K. Nishibata, "Role of the oxygen uptake efficiency slope in evaluating exercise tolerance," Archives of Disease in Childhood, vol. 81, no. 1, pp. 73-75, 1999.

[168] T. P. Olson, M. J. Joyner, and B. D. Johnson, "Influence of locomotor muscle metaboreceptor stimulation on the ventilatory response to exercise in heart failure," Circulation: Heart Failure, vol. 3, no. 2, pp. 212-219, 2010.

[169] X. G. Sun, J. E. Hansen, and W. W. Stringer, "Oxygen uptake efficiency plateau: physiology and reference values," European Journal of Applied Physiology, pp. 1-10, 2011.

[170] B. J. Whipp and S. A. Ward, "The coupling of ventilation to pulmonary gas exchange during exercise," in Pulmonary Physiology and Pathophysiology of Exercise, B. J. Whipp and K. Wasserman, Eds., pp. 271-307, Dekker, New York, NY, USA, 1991.

[171] C. Van Laethem, J. Bartunek, M. Goethals, P. Nellens, E. Andries, and M. Vanderheyden, "Oxygen uptake efficiency slope, a new submaximal parameter in evaluating exercise capacity in chronic heart failure patients," American Heart Journal, vol. 149, no. 1, pp. 175-180, 2005.

[172] C. Van Laethem, J. De Sutter, W. Peersman, and P. Calders, "Intratest reliability and test-retest reproducibility of the oxygen uptake efficiency slope in healthy participants," European Journal of Cardiovascular Prevention and Rehabilitation, vol. 16, no. 4, pp. 493-498, 2009.

[173] W. Williamson, J. Fuld, K. Westgate, K. Sylvester, U. Ekelund, and S. Brage, "Validity of reporting oxygen uptake efficiency slope from submaximal exercise using respiratory exchange ratio as secondary criterion," Pulmonary Medicine, vol. 2012, Article ID 874020, 8 pages, 2012.

[174] M. Gruet, J. Brisswalter, L. Mely, and J. M. Vallier, "Clinical utility of the oxygen uptake efficiency slope in cystic fibrosis patients," Journal of Cystic Fibrosis, vol. 9, no. 5, pp. 307-313, 2010.

[175] B. J. Phypers, D. Robiony-Rogers, R. M. Pickering, and A. L. Garden, "Test-retest reliability of the oxygen uptake efficiency slope in surgical patients," Anaesthesia, vol. 66, no. 8, pp. 659666, 2011.

[176] R. Baba, N. Kubo, Y. Morotome, and S. Iwagaki, "Reproducibility of the oxygen uptake efficiency slope in normal healthy subjects," Journal of Sports Medicine and Physical Fitness, vol. 39, no. 3, pp. 202-206, 1999.

[177] M. Akkerman, M. Van Brussel, E. Hulzebos, L. Vanhees, P. J. M. Helders, and T. Takken, "The oxygen uptake efficiency slope: what do we know?" Journal of Cardiopulmonary Rehabilitation and Prevention, vol. 30, no. 6, pp. 357-373, 2010.

[178] R. Arena, J. Myers, L. Hsu et al., "The minute ventilation/carbon dioxide production slope is prognostically superior to the oxygen uptake efficiency slope," Journal of Cardiac Failure, vol. 13, no. 6, pp. 462-469, 2007.

[179] J. Myers, R. Arena, F. Dewey et al., "A cardiopulmonary exercise testing score for predicting outcomes in patients with heart failure," American Heart Journal, vol. 156, no. 6, pp. 1177-1183, 2008.

[180] B. C. Bongers, E. H. Hulzebos, B. G. Arets, and T. Takken, "Validity of the oxygen uptake efficiency slope in children with cystic fibrosis and mild-to-moderate airflow obstruction," Pediatric Exercise Science, vol. 24, pp. 129-141, 2012.

[181] B. J. Whipp, H. B. Rossiter, S. A. Ward et al., "Simultaneous determination of muscle and $\mathrm{O}_{2}$ uptake kinetics during whole body NMR spectroscopy," Journal of Applied Physiology, vol. 86, no. 2, pp. 742-747, 1999.

[182] J. M. Hagberg, J. P. Mullin, and F. J. Nagle, "Effect of work intensity and duration on recovery $\mathrm{O}_{2}$," Journal of Applied Physiology Respiratory Environmental and Exercise Physiology, vol. 48 , no. 3, pp. 540-544, 1980. 
[183] G. A. Gaesser and G. A. Brooks, "Metabolic bases of excess post-exercise oxygen consumption: a review," Medicine Science in Sports Exercise, vol. 16, pp. 29-43, 1984.

[184] T. Yoshida and B. J. Whipp, "Dynamic asymmetries of cardiac output transients in response to muscular exercise in man," Journal of Physiology, vol. 480, no. 2, pp. 355-359, 1994.

[185] P. De Groote, A. Millaire, E. Decoulx, O. Nugue, P. Guimier, and G. Ducloux, "Kinetics of oxygen consumption during and after exercise in patients with dilated cardiomyopathy: new markers of exercise intolerance with clinical implications," Journal of the American College of Cardiology, vol. 28, no. 1, pp. 168-175, 1996.

[186] A. Koike, T. Yajima, H. Adachi et al., "Evaluation of exercise capacity using submaximal exercise at a constant work rate in patients with cardiovascular disease," Circulation, vol. 91, no. 6, pp. 1719-1724, 1995.

[187] H. M. Kemps, G. Schep, M. L. Zonderland et al., "Are oxygen uptake kinetics in chronic heart failure limited by oxygen delivery or oxygen utilization?" International Journal of Cardiology, vol. 142, no. 2, pp. 138-144, 2010.

[188] S. Nanas, J. Nanas, C. Kassiotis et al., "Early recovery of oxygen kinetics after submaximal exercise test predicts functional capacity in patients with chronic heart failure," European Journal of Heart Failure, vol. 3, no. 6, pp. 685-692, 2001.

[189] S. Nanas, J. Nanas, C. Kassiotis et al., "Respiratory muscles performance is related to oxygen kinetics during maximal exercise and early recovery in patients with congestive heart failure," Circulation, vol. 100, no. 5, pp. 503-508, 1999.

[190] A. Cohen-Solal, T. Laperche, D. Morvan, M. Geneves, B. Caviezel, and R. Gourgon, "Prolonged kinetics of recovery of oxygen consumption after maximal graded exercise in patients with chronic heart failure: analysis with gas exchange measurements and NMR spectroscopy," Circulation, vol. 91, no. 12, pp. 2924-2932, 1995.

[191] H. Daida, T. G. Allison, B. D. Johnson, R. W. Squires, and G. T. Gau, "Further increase in oxygen uptake during early active recovery following maximal exercise in chronic heart failure," Chest, vol. 109, no. 1, pp. 47-51, 1996.

[192] A. Cohen-Solal, D. Czitrom, M. Geneves, and R. Gourgon, "Delayed attainment of peak oxygen consumption after the end of exercise in patients with chronic heart failure," International Journal of Cardiology, vol. 60, no. 1, pp. 23-29, 1997.

[193] H. Takaki, S. Sakuragi, N. Nagaya et al., "Postexercise $\mathrm{VO}_{2}$ "Hump" phenomenon as an indicator for inducible myocardial ischemia in patients with acute anterior myocardial infarction," International Journal of Cardiology, vol. 111, no. 1, pp. 67-74, 2006.

[194] C. D. Kriatselis, S. Nedios, S. Kelle, S. Helbig, M. Gottwik, and C. von Bary, "Oxygen kinetics and heart rate response during early recovery from exercise in patients with heart failure," Cardiology Research and Practice, vol. 2012, Article ID 512857, 7 pages, 2012.

[195] A. Tajima, H. Itoh, N. Osada et al., "Oxygen uptake kinetics during and after exercise are useful markers of coronary artery disease in patients with exercise electrocardiography suggesting myocardial ischemia," Circulation Journal, vol. 73, no. 10, pp. 1864-1870, 2009.

[196] T. W. Chick, T. G. Cagle, F. A. Vegas, J. K. Poliner, and G. H. Murata, "Recovery of gas exchange variables and heart rate after maximal exercise in COPD," Chest, vol. 97, no. 2, pp. 276-279, 1990.

[197] E. Pouliou, S. Nanas, A. Papamichalopoulos et al., "Prolonged oxygen kinetics during early recovery from maximal exercise in adult patients with cystic fibrosis," Chest, vol. 119, no. 4, pp. 1073-1078, 2001.

[198] I. Levinger, M. Varley, G. Jerums, D. L. Hare, and S. Selig, "Oxygen $\left(\mathrm{O}_{2}\right)$ kinetics during early recovery from peak exercise in patients with Type 2 diabetes," Diabetic Medicine, vol. 28, no. 5, pp. 612-617, 2011.

[199] V. A. Convertino, D. J. Goldwater, and H. Sandler, " $\mathrm{VO}_{2}$ kinetics on constant-load exercise following bed-rest-induced deconditioning," Journal of Applied Physiology Respiratory Environmental and Exercise Physiology, vol. 57, no. 5, pp. 1545-1550, 1984.

[200] Y. Tanabe, M. Takahashi, Y. Hosaka, M. Ito, E. Ito, and K. Suzuki, "Prolonged recovery of cardiac output after maximal exercise in patients with chronic heart failure," Journal of the American College of Cardiology, vol. 35, no. 5, pp. 1228-1236, 2000.

[201] A. Giardini, A. Donti, S. Specchia et al., "Recovery kinetics of oxygen uptake is prolonged in adults with an atrial septal defect and improves after transcatheter closure," American Heart Journal, vol. 147, no. 5, pp. 910-914, 2004.

[202] R. L. Johnson, "Gas exchange efficiency in congestive heart failure," Circulation, vol. 101, no. 24, pp. 2774-2776, 2000.

[203] A. Oren, K. Wasserman, J. A. Davis, and B. J. Whipp, "Effect of $\mathrm{CO}_{2}$ set point on ventilatory response to exercise," Journal of Applied Physiology Respiratory Environmental and Exercise Physiology, vol. 51, no. 1, pp. 185-189, 1981.

[204] K. Wasserman, Y. Y. Zhang, A. Gilt et al., "Lung function and exercise gas exchange in chronic heart failure," Circulation, vol. 96, no. 7, pp. 2221-2227, 1997.

[205] D. Y. Sue, "Excess ventilation during exercise and prognosis in chronic heart failure," American Journal of Respiratory and Critical Care Medicine, vol. 183, no. 10, pp. 1302-1310, 2011.

[206] M. Guazzi, G. Reina, G. Tumminello, and M. D. Guazzi, "Exercise ventilation inefficiency and cardiovascular mortality in heart failure: the critical independent prognostic value of the arterial $\mathrm{CO}_{2}$ partial pressure," European Heart Journal, vol. 26, no. 5, pp. 472-480, 2005.

[207] R. Arena, J. Myers, S. S. Aslam, E. B. Varughese, and M. A. Peberdy, "Technical considerations related to the minute ventilation/carbon dioxide output slope in patients with heart failure," Chest, vol. 124, no. 2, pp. 720-727, 2003.

[208] J. A. Davis, B. J. Whipp, and K. Wasserman, "The relation of ventilation to metabolic rate during moderate exercise in man," European Journal of Applied Physiology and Occupational Physiology, vol. 44, no. 2, pp. 97-108, 1980.

[209] F. X. Kleber, G. Vietzke, K. D. Wernecke et al., "Impairment of ventilatory efficiency in heart failure: prognostic impact," Circulation, vol. 101, no. 24, pp. 2803-2809, 2000.

[210] M. Robbins, G. Francis, F. J. Pashkow et al., "Ventilatory and heart rate responses to exercise better predictors of heart failure mortality than peak oxygen consumption," Circulation, vol. 100, no. 24, pp. 2411-2417, 1999.

[211] J. Myers, R. Arena, F. Dewey et al., "A cardiopulmonary exercise testing score for predicting outcomes in patients with heart failure," American Heart Journal, vol. 156, no. 6, pp. 1177-1183, 2008.

[212] J. Myers, R. Arena, R. B. Oliveira et al., "The lowest VE/ $/ \mathrm{VCO}_{2}$ ratio during exercise as a predictor of outcomes in patients with heart failure," Journal of Cardiac Failure, vol. 15, no. 9, pp. 756$762,2009$.

[213] M. Schwaiblmair, C. Faul, W. von Scheidt, and T. Berghaus, "Ventilatory efficiency testing as prognostic value in patients 
with pulmonary hypertension," BMC Pulmonary Medicine, vol. 12, p. 23, 2012.

[214] M. Guazzi, J. Myers, M. Vicenzi et al., "Cardiopulmonary exercise testing characteristics in heart failure patients with and without concomitant chronic obstructive pulmonary disease," American Heart Journal, vol. 160, no. 5, pp. 900-905, 2010.

[215] G. Deboeck, G. Niset, M. Lamotte, J. L. Vachiéry, and R. Naeije, "Exercise testing in pulmonary arterial hypertension and in chronic heart failure," European Respiratory Journal, vol. 23, no. 5, pp. 747-751, 2004.

[216] Z. Zhai, K. Murphy, H. Tighe et al., "Differences in ventilatory inefficiency between pulmonary arterial hypertension and chronic thromboembolic pulmonary hypertension," Chest, vol. 140, no. 5, pp. 1284-1291, 2011.

[217] M. A. Roman, J. D. Casaburi, J. Porszasz, and R. Casaburi, "Noninvasive assessment of normality of V, (D)/V (T) in clinical cardiopulmonary exercise testing utilizing incremental cycle ergometry," European Journal of Applied Physiology, vol. 113, no. 1, pp. 33-40, 2012.

[218] M. I. Zimmerman, A. Miller, L. K. Brown, A. Bhuptani, M. F. Sloane, and A. S. Teirstein, "Estimated vs actual values for dead space/tidal volume ratios during incremental exercise in patients evaluated for dyspnea," Chest, vol. 106, no. 1, pp. 131136, 1994.

[219] A. Matsumoto, H. Itoh, Y. Eto et al., "End-tidal $\mathrm{CO}_{2}$ pressure decreases during exercise in cardiac patients," Journal of the American College of Cardiology, vol. 36, no. 1, pp. 242-249, 2000.

[220] J. Myers, P. Gujja, S. Neelagaru et al., "End-tidal $\mathrm{CO}_{2}$ pressure and cardiac performance during exercise in heart failure," Medicine and science in sports and exercise, vol. 41, no. 1, pp. 1925, 2009.

[221] P. W. Jones, W. French, M. L. Weissman, and K. Wasserman, "Ventilatory responses to cardiac output changes in patients with pacemakers," Journal of Applied Physiology Respiratory Environmental and Exercise Physiology, vol. 51, no. 5, pp. 11031107, 1981.

[222] R. Arena, J. Myers, J. Abella et al., "Prognostic value of timing and duration characteristics of exercise oscillatory ventilation in patients with heart failure," The Journal of Heart and Lung Transplantation, vol. 27, no. 3, pp. 341-347, 2008.

[223] L. J. Olson, A. M. Arruda-Olson, V. K. Somers, C. G. Scott, and B. D. Johnson, "Exercise oscillatory ventilation: instability of breathing control associated with advanced heart failure," Chest, vol. 133, no. 2, pp. 474-481, 2008.

[224] A. Koike, N. Shimizu, A. Tajima et al., "Relation between oscillatory ventilation at rest before cardiopulmonary exercise testing and prognosis in patients with left ventricular dysfunction," Chest, vol. 123, no. 2, pp. 372-379, 2003.

[225] I. Ben-Dov, K. E. Sietsema, R. Casaburi, and K. Wasserman, "Evidence that circulatory oscillations accompany ventilatory oscillations during exercise in patients with heart failure," The American Review of Respiratory Disease, vol. 145, no. 4 I, pp. 776-781, 1992.

[226] P. Ponikowski, S. D. Anker, T. P. Chua et al., "Oscillatory breathing patterns during wakefulness in patients with chronic heart failure: clinical implications and role of augmented peripheral chemosensitivity," Circulation, vol. 100, no. 24, pp. 2418-2424, 1999.

[227] D. P. Francis, K. Willson, L. C. Davies, A. J. S. Coats, and M. Piepoli, "Quantitative general theory for periodic breathing in chronic heart failure and its clinical implications," Circulation, vol. 102, no. 18, pp. 2214-2221, 2000.
[228] P. Hanly, N. Zuberi, and R. Gray, "Pathogenesis of cheyne-stokes respiration in patients with congestive heart failure: relationship to arterial $\mathrm{PCO}_{2}$," Chest, vol. 104, no. 4, pp. 1079-1084, 1993.

[229] S. Javaheri, "A mechanism of central sleep apnea in patients with heart failure," The New England Journal of Medicine, vol. 341, no. 13, pp. 949-954, 1999.

[230] P. Ponikowski, T. P. Chua, S. D. Anker et al., "Peripheral chemoreceptor hypersensitivity an ominous sign in patients with chronic heart failure," Circulation, vol. 104, no. 5, pp. 544549, 2001.

[231] M. H. Sanders, "Article reviewed: a mechanism of central sleep apnea in patients with heart failure," Sleep Medicine, vol. 1, no. 1, pp. 63-64, 2000.

[232] J. P. Ribeiro, "Periodic breathing in heart failure: bridging the gap between the sleep laboratory and the exercise laboratory," Circulation, vol. 113, no. 1, pp. 9-10, 2006.

[233] S. Andreas, "Central sleep apnea and chronic heart failure," Sleep, vol. 23, no. 4, pp. S220-S223, 2000.

[234] M. F. Piepoli, A. Kaczmarek, D. P. Francis et al., "Reduced peripheral skeletal muscle mass and abnormal reflex physiology in chronic heart failure," Circulation, vol. 114, no. 2, pp. 126-134, 2006.

[235] D. P. Francis, L. C. Davies, M. Piepoli, M. Rauchhaus, P. Ponikowski, and A. J. S. Coats, "Origin of oscillatory kinetics of respiratory gas exchange in chronic heart failure," Circulation, vol. 100, no. 10, pp. 1065-1070, 1999.

[236] M. Guazzi, R. Raimondo, M. Vicenzi et al., "Exercise oscillatory ventilation may predict sudden cardiac death in heart failure patients," Journal of the American College of Cardiology, vol. 50, no. 4, pp. 299-308, 2007.

[237] J. P. Ribeiro, A. Knutzen, M. B. Rocco, L. H. Hartley, and W. S. Colucci, "Periodic breathing during exercise in severe heart failure: reversal with milrinone or cardiac transplantation," Chest, vol. 92, no. 3, pp. 555-556, 1987.

[238] L. Ingle, A. Isted, K. K. Witte, J. G. F. Cleland, and A. L. Clark, "Impact of different diagnostic criteria on the prevalence and prognostic significance of exertional oscillatory ventilation in patients with chronic heart failure," European Journal of Cardiovascular Prevention and Rehabilitation, vol. 16, no. 4, pp. 451-456, 2009.

[239] M. Guazzi, R. Arena, A. Ascione, M. Piepoli, and M. D. Guazzi, "Exercise oscillatory breathing and increased ventilation to carbon dioxide production slope in heart failure: an unfavorable combination with high prognostic value," American Heart Journal, vol. 153, no. 5, pp. 859-867, 2007.

[240] M. Guazzi, J. Myers, M. A. Peberdy, D. Bensimhon, P. Chase, and R. Arena, "Exercise oscillatory breathing in diastolic heart failure: prevalence and prognostic insights," European Heart Journal, vol. 29, no. 22, pp. 2751-2759, 2008.

[241] C. B. Kremser, M. F. O’Toole, and A. R. Leff, "Oscillatory hyperventilation in severe congestive heart failure secondary to idiopathic dilated cardiomyopathy or to ischemic cardiomyopathy," The American Journal of Cardiology, vol. 59, no. 8, pp. 900905, 1987.

[242] K. Miyagi, H. Asanoi, S. Ishizaka, T. Kameyama, and S. Sasayama, "Limited value of anaerobic threshold for assessing functional capacity in patients with heart failure," Clinical Cardiology, vol. 16, no. 2, pp. 133-137, 1993.

[243] P. Dall'Ago, G. R. S. Chiappa, H. Guths, R. Stein, and J. P. Ribeiro, "Inspiratory muscle training in patients with heart failure and inspiratory muscle weakness: a randomized trial," Journal of the American College of Cardiology, vol. 47, no. 4, pp. 757-763, 2006. 
[244] M. Zurek, U. Corra, M. F. Piepoli, R. K. Binder, H. Saner, and J. P. Schmid, "Exercise training reverses exertional oscillatory ventilation in heart failure patients," European Respiratory Journal, vol. 40, no. 5, pp. 1238-1244, 2012.

[245] E. R. Winkelmann, G. R. Chiappa, C. O. C. Lima, P. R. N. Viecili, R. Stein, and J. P. Ribeiro, "Addition of inspiratory muscle training to aerobic training improves cardiorespiratory responses to exercise in patients with heart failure and inspiratory muscle weakness," American Heart Journal, vol. 158, no. 5, pp. 768-el, 2009.

[246] M. H. Laughlin, "Cardiovascular response to exercise," The American Journal of Physiology, vol. 277, no. 6, pp. S244-S259, 1999.

[247] M. E. Bodner and E. C. Rhodes, "A review of the concept of the heart rate deflection point," Sports Medicine, vol. 30, no. 1, pp. 31-46, 2000.

[248] M. Bevilacqua, S. Savonitto, E. Bosisio et al., "Role of the frank-starling mechanism in maintaining cardiac output during increasing levels of treadmill exercise in $\beta$-blocked normal men," The American Journal of Cardiology, vol. 63, no. 12, pp. 853-857, 1989.

[249] T. D. Miller, R. J. Gibbons, R. W. Squires, T. G. Allison, and G. T. Gau, "Sinus node deceleration during exercise as a marker of significant narrowing of the right coronary artery," The American Journal of Cardiology, vol. 71, no. 4, pp. 371-373, 1993.

[250] U. P. Jorde, T. J. Vittorio, M. E. Kasper et al., "Chronotropic incompetence, $\beta$-blockers, and functional capacity in advanced congestive heart failure: time to pace?" European Journal of Heart Failure, vol. 10, no. 1, pp. 96-101, 2008.

[251] G. L. Pierpont and E. J. Voth, "Assessing autonomic function by analysis of heart rate recovery from exercise in healthy subjects," The American Journal of Cardiology, vol. 94, no. 1, pp. 64-68, 2004.

[252] K. Imai, H. Sato, M. Hori et al., "Vagally mediated heart rate recovery after exercise is accelerated in athletes but blunted in patients with chronic heart failure," Journal of the American College of Cardiology, vol. 24, no. 6, pp. 1529-1535, 1994.

[253] N. Seshadri, T. R. Gildea, K. McCarthy, C. Pothier, M. S. Kavuru, and M. S. Lauer, "Association of an abnormal exercise heart rate recovery with pulmonary function abnormalities," Chest, vol. 125, no. 4, pp. 1286-1291, 2004.

[254] S. Dimopoulos, M. Anastasiou-Nana, F. Katsaros et al., "Impairment of autonomic nervous system activity in patients with pulmonary arterial hypertension: a case control study," Journal of Cardiac Failure, vol. 15, no. 10, pp. 882-889, 2009.

[255] K. P. Savonen, V. Kiviniemi, D. E. Laaksonen et al., "Two-minute heart rate recovery after cycle ergometer exercise and all-cause mortality in middle-aged men," Journal of Internal Medicine, vol. 270, no. 6, pp. 589-596, 2011.

[256] L. P. Cahalin, R. Arena, and M. Guazzi, "Comparison of heart rate recovery after the six-minute walk test to cardiopulmonary exercise testing in patients with heart failure and reduced and preserved ejection fraction," The American Journal of Cardiology, vol. 110, no. 3, pp. 467-468, 2012.

[257] O. A. Minai, R. Gudavalli, S. Mummadi, X. Liu, K. McCarthy, and R. A. Dweik, "Heart rate recovery predicts clinical worsening in patients with pulmonary arterial hypertension," American Journal of Respiratory and Critical Care Medicine, vol. 185, no. 4, pp. 400-408, 2012.

[258] B. Aijaz, R. W. Squires, R. J. Thomas, B. D. Johnson, and T. G. Allison, "Predictive value of heart rate recovery and peak oxygen consumption for long-term mortality in patients with coronary heart disease," The American Journal of Cardiology, vol. 103, no. 12, pp. 1641-1646, 2009.

[259] L. E. Ritt, R. B. Oliveira, J. Myers et al., "Patients with heart failure in the, "intermediate range" of peak oxygen uptake: additive value of heart rate recovery and the minute ventilation/carbon dioxide output slope in predicting mortality," Journal of Cardiopulmonary Rehabilitation and Prevention, vol. 32, pp. 141-146, 2012.

[260] J. L. Liu, S. Irvine, I. A. Reid, K. P. Patel, and I. H. Zucker, "Chronic exercise reduces sympathetic nerve activity in rabbits with pacing-induced heart failure: a role for angiotensin II," Circulation, vol. 102, no. 15, pp. 1854-1862, 2000.

[261] D. Lucini, R. V. Milani, G. Costantino, C. J. Lavie, A. Porta, and M. Pagani, "Effects of cardiac rehabilitation and exercise training on autonomic regulation in patients with coronary artery disease," American Heart Journal, vol. 143, no. 6, pp. 977983, 2002.

[262] J. J. Hai, C. W. Siu, H. H. Ho, S. W. Li, S. Lee, and H. F. Tse, "Relationship between changes in heart rate recovery after cardiac rehabilitation on cardiovascular mortality in patients with myocardial infarction," Heart Rhythm, vol. 7, no. 7, pp. 929936, 2010.

[263] M. T. Maeder, P. Ammann, H. Rickli, and H. P. Brunner-La Rocca, "Impact of the exercise mode on heart rate recovery after maximal exercise," European Journal of Applied Physiology, vol. 105, no. 2, pp. 247-255, 2009. 


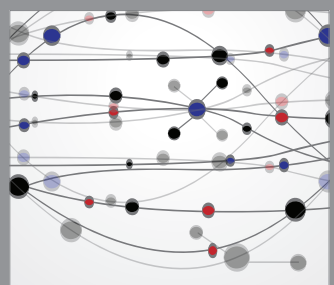

The Scientific World Journal
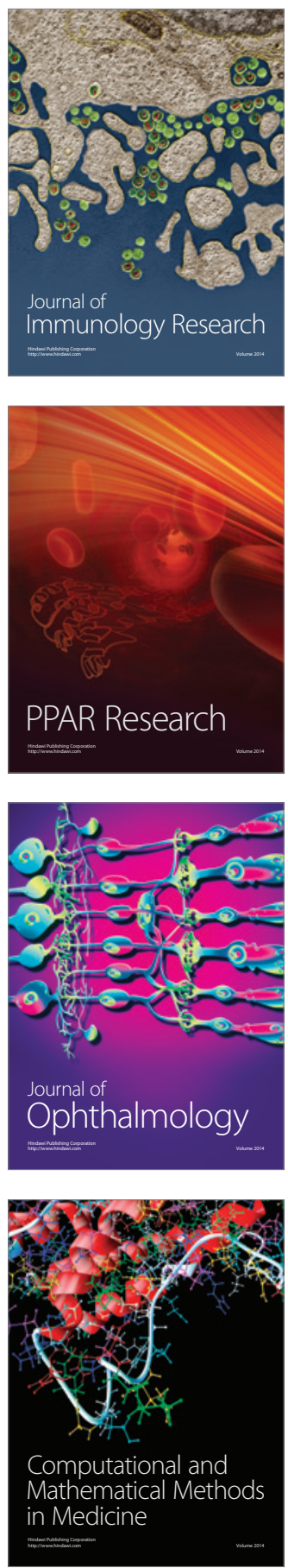

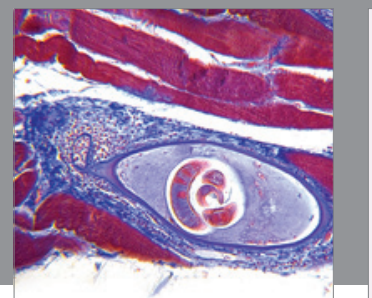

Gastroenterology

Research and Practice
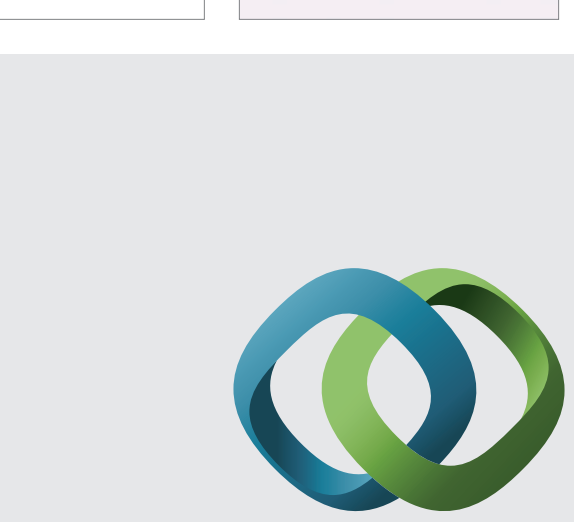

\section{Hindawi}

Submit your manuscripts at

http://www.hindawi.com
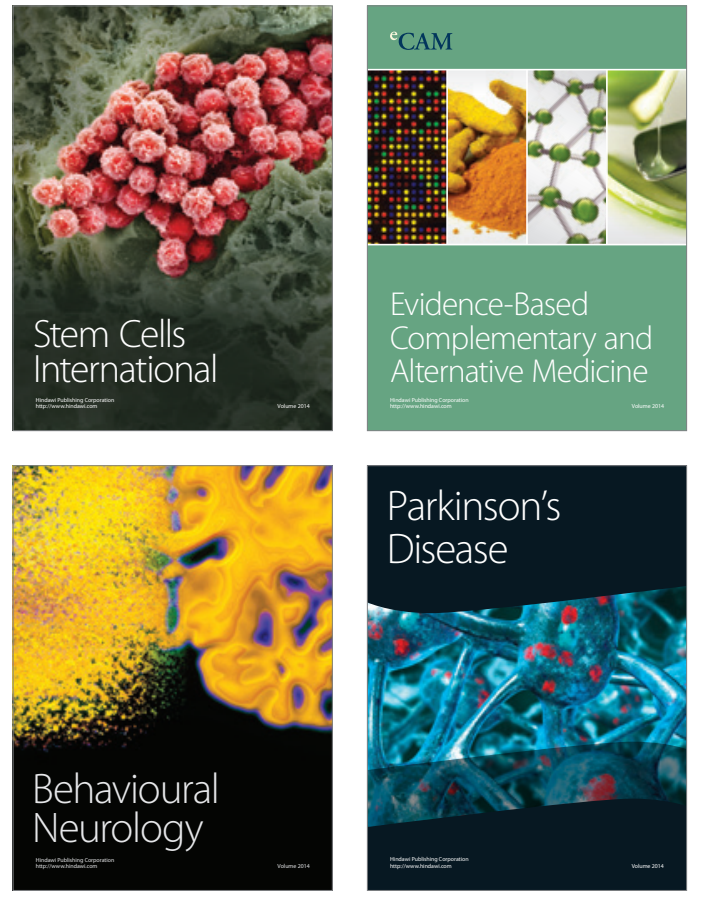
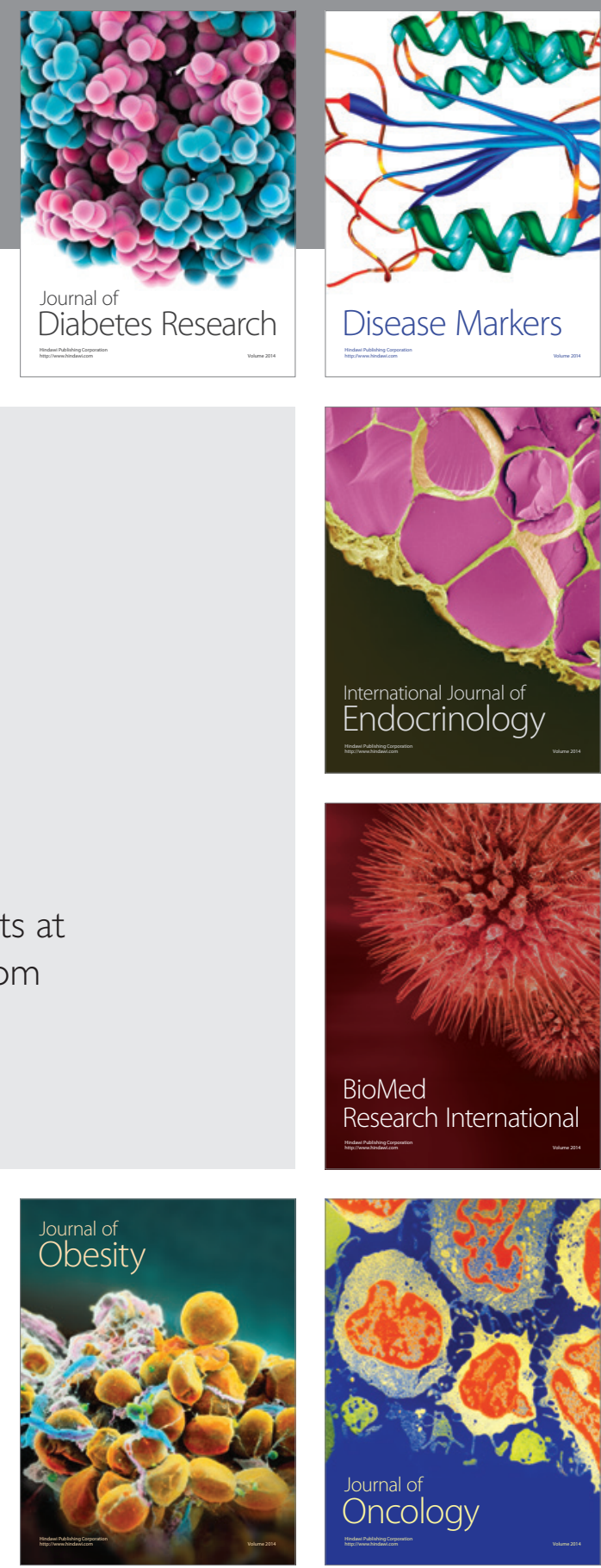

Disease Markers
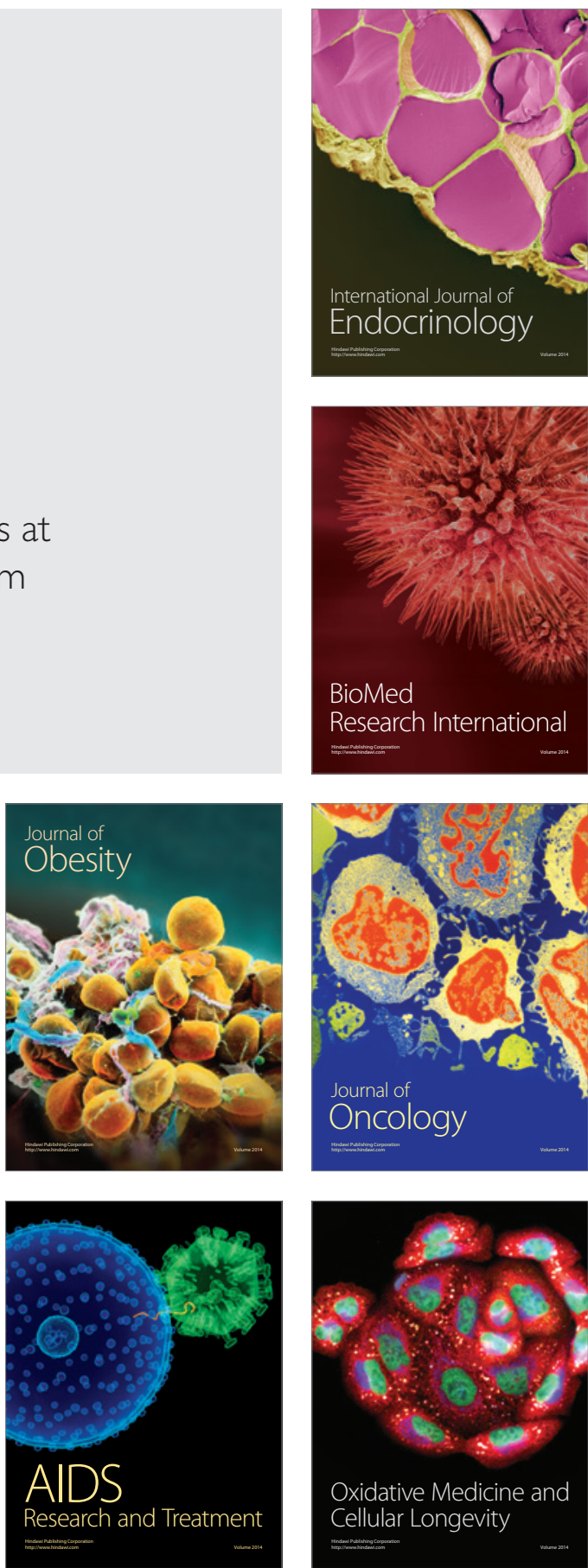